\title{
Is postoperative nasal packing after septoplasty safe? A systematic review and meta-analysis of randomized controlled studies*
}

\author{
Chernkwan K. Titirungruang, Natamon Charakorn, Busarakum Chaitusaney, \\ Prakobkiat Hirunwiwatkul
}

Department of Otolaryngology, Faculty of Medicine, Chulalongkorn University, Bangkok, Thailand
Rhinology 59: 0, 000 - 000, 2021 https://doi.org/10.4193/Rhin21.057

*Received for publication:

February 7, 2021

Accepted: March 30, 2021

\section{Abstract}

Objectives: To systemically review and compare post-septoplasty complications between total nasal packing and other techniques.

Methodology: We searched electronic databases (PubMed, Scopus, and Cochrane Library) and additional sources. The most recent search was on November 30th, 2020. Randomized controlled trials (RCTs) comparing adverse events after post-septoplasty nasal packing versus other techniques were included. The outcomes were adverse events, including respiratory distress, oxygen desaturation, pain severity, bleeding, hematoma, sleep disturbance, infection, crusting, epiphora, dysphagia, perforation, adhesion, and residual septal deviation.

Results: There were 47 studies (4,087 participants) in this systematic review. Nasal packing was more likely to cause adverse events than other techniques. There were significant increases in respiratory distress, pain, sleep disturbance, crusting, epiphora, dysphagia, and adhesion. There were no statistically significant differences in oxygen desaturation, bleeding, hematoma, infection, perforation, and residual septal deviation. Subgroup analysis found that trans-septal suture was less likely to cause postoperative complications compared with total nasal packing.

Conclusion: Nasal packing after septoplasty was more likely to cause adverse events, including respiratory distress, pain, sleep disturbance, crusting, epiphora, dysphagia, and adhesion. Furthermore, there were no benefits of nasal packing in preventing bleeding, hematoma, and residual septal deviation when compared with other techniques. Routine nasal packing after septoplasty should be avoided. Trans-septal suture should be considered instead.

Key words: complication, meta-analysis, nasal packing, septoplasty, trans-septal suture

\section{Introduction}

Septoplasty is a common procedure for treating nasal obstruction caused by nasal septal deviation. Traditionally, bilateral anterior nasal packing is performed following septoplasty to prevent bleeding, septal hematoma, and adhesion between the septum and lateral nasal wall. Furthermore, it is thought to reduce the risk of residual septal deviation by stabilizing the remaining septum during the healing process ${ }^{(1)}$. However, totally occlusive nasal packing has a tendency to cause adverse events, including respiratory distress, pain, infection, sleep disturbance, crusting, epiphora, and dysphagia. The routine nasal packing after septoplasty has been questioned in the past decades. Many post-operative techniques have been introduced as alternatives to the nasal packing, such as trans-septal suturing, nasal splinting, trans-septal stapling, and inter-septal fibrin glue, etc. Trans-septal suture technique has been promoted since the 1980 s and currently is the most widely used. This procedure is used to prevent the formation of septal hematoma, close the tear mucosa, and support the remaining cartilage ${ }^{(2)}$. However, tight trans-septal sutures can increase the risk of septal perfo- 
ration $^{(1)}$. Intranasal septal splints are also used as an alternative to nasal packing to decrease bleeding, prevent adhesion, and stabilize the remaining septum ${ }^{(3)}$.

Previous meta-analyses compared the risks of post-septoplasty complications between nasal packing and trans-septal suture. There were no significant differences in the risks of bleeding, hematoma, perforation, and residual septal deviation ${ }^{(4-7)}$, while the risks of adhesion, and infection were inconclusive ${ }^{(4-7)}$. Transseptal suture significantly decreased postoperative pain compared to the nasal packing ${ }^{(5-7)}$. Nasal splinting was also analyzed in 2 meta-analyses which included both trans-septal suture and nasal splinting in the non-packing intervention. However, the subgroup analysis of nasal splinting was not done ${ }^{(4,6)}$. A metaanalysis by Banglawala et al., which included 2 randomized controlled trials (RCTs) and 12 observational studies found that post-septoplasty nasal packing did not seem to cause adverse cardiopulmonary changes ${ }^{(8)}$.

There are many RCTs that have not been included in the previous meta-analyses. In addition, many adverse events caused by post-septoplasty nasal packing have not been analyzed, especially respiratory distress, which could cause a serious morbidity and prolong hospitalization. This meta-analysis aimed to systemically review and compare post-operative complications between the post-septoplasty total nasal packing and other techniques.

\section{Materials and methods}

Information sources and search strategy

Three authors (CKT, NC, and BC) independently conducted searches for published, unpublished, and ongoing RCTs from electronic databases, via PubMed, Scopus, and the Cochrane library. The search began on November 15th, and the most recent search was on November 30th, 2020. The search terms were "(septoplasty OR (nasal septum surgery)) AND ((nasal packing) OR (trans-septal suture) OR (nasal splint))." We manually searched other sources from the Chulalongkorn Medical Library and those existing primary researches in previous meta-analyses.

Study selection

The inclusion criteria were RCTs relating to: 1 ) patients in all age groups who underwent septoplasty with or without turbinoplasty, 2) comparisons between post-operative nasal packing and other techniques, 3 ) at least one of the following post-operative outcome measures: respiratory distress, oxygen desaturation, pain severity, bleeding, hematoma, sleep disturbance, infection, crusting, epiphora, dysphagia, perforation, adhesion, and residual septal deviation, and 4) published in any language. Articles with the following exclusion criteria were eliminated if: 1) the patients underwent additional nasal surgery other than septoplasty and turbinoplasty 2) the reported data were incorrect or incomplete that could not provide outcome measures, and 3) repeated published literature.

Three authors (CKT, NC, and BC) independently reviewed titles and abstracts of the articles and selected the articles that met the selection criteria. Full-text of the selected articles were reviewed. The articles in other languages were translated. If there was any insufficient data, the corresponding author of that article was contacted for further information. Discrepancies were resolved by discussion among the authors or the decision of the fourth author $(\mathrm{PH})$.

\section{Quality assessment}

Three authors (CKT, NC, and BC) independently evaluated quality of the included studies by assessing the risks of bias in accordance with the Cochrane Handbook for Systematic Reviews of Interventions Version 6.1. Risk of bias in each study was assessed in the following domains: selection bias, performance bias, detection bias, attrition bias, and reporting bias. Each domain was classified as low risk, high risk, or unclear risk. Low risk or high risk of bias was determined if the described methods met the criteria of low risk of bias or high risk of bias of that domain respectively. Unclear risk of bias was selected when there was either a lack of information or uncertainty over the potential for bias. Discrepancies were resolved by discussion or through a fourth investigator $(\mathrm{PH})$.

\section{Data extraction}

Two authors (CKT and NC) independently extracted and recorded the data. The extracted data were age of the patient, type of anesthesia, nasal packing materials, nasal packing duration, other techniques, follow-up time, and adverse events as follows: respiratory distress, oxygen saturation, pain severity score, bleeding, hematoma, sleep disturbance events, sleep disturbance score, infection, crusting, epiphora, dysphagia, perforation, adhesion, and residual septal deviation.

\section{Statistical analysis}

Data were pooled for meta-analysis. Subgroup analyses by alternative technique were performed. Odds ratio (OR) and 95\% confidence interval $(\mathrm{Cl})$ were used for dichotomous data. Continuous data were presented as mean difference (MD) or standardized mean difference (SMD), standard deviation (SD) and 95\% $\mathrm{Cl}$. The standard error, median, range, or $95 \% \mathrm{Cl}$ was imputed if the SD was not reported. Discrepancies in treatment effects among different trials were assessed using a heterogeneity (I2) statistic. An 12 of $<40 \%, 40-60 \%$ and $>60 \%$ represented low, moderate and substantial heterogeneity, respectively. When a heterogeneity was low, a fixed-effect model was used. A random effects model was used if a heterogeneity was high for a more conservative estimate of the differences. All statistical assessments were conducted using the Review Manager 5.4 software. Sensitivity analyses were performed based the following: high 


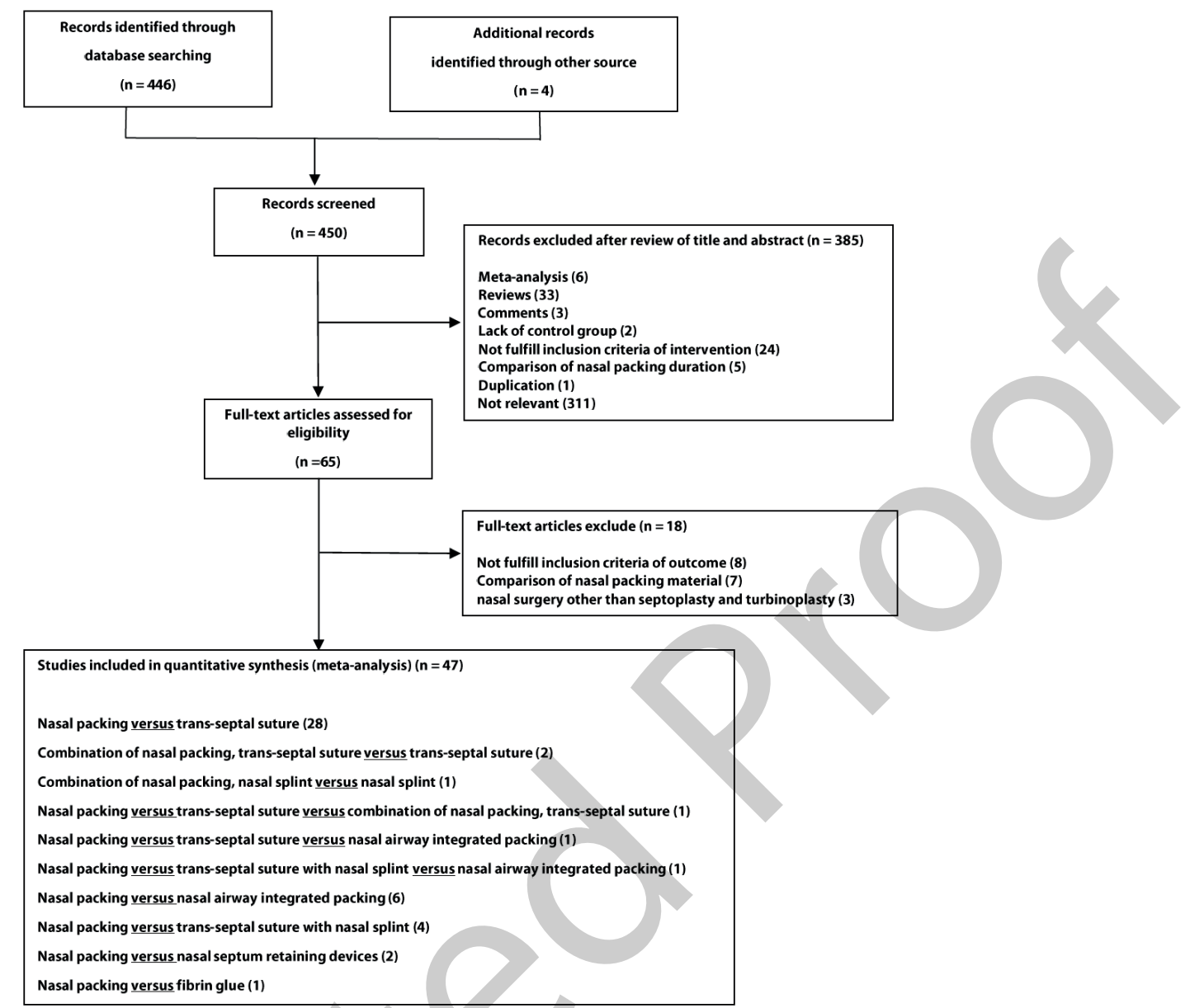

Figure 1. PRISMA flow diagram ot study searchıng strategy

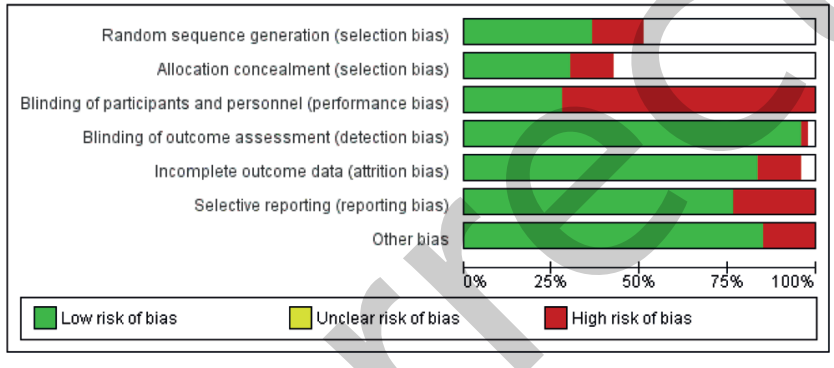

Figure 2. Quality assessment summary for included studies: risk of bias graph.

methodological quality study, exclusion of studies that caused heterogeneity, and exclusion of studies with different pain score systems.

\section{Results}

Study selection

A total of 450 references were retrieved. After the titles and abstracts were reviewed, 385 studies were excluded from the study. Full-text of the remaining 65 RCTs were reviewed, 47 of which met the selection criteria and were included in this metaanalysis (Figure 1).
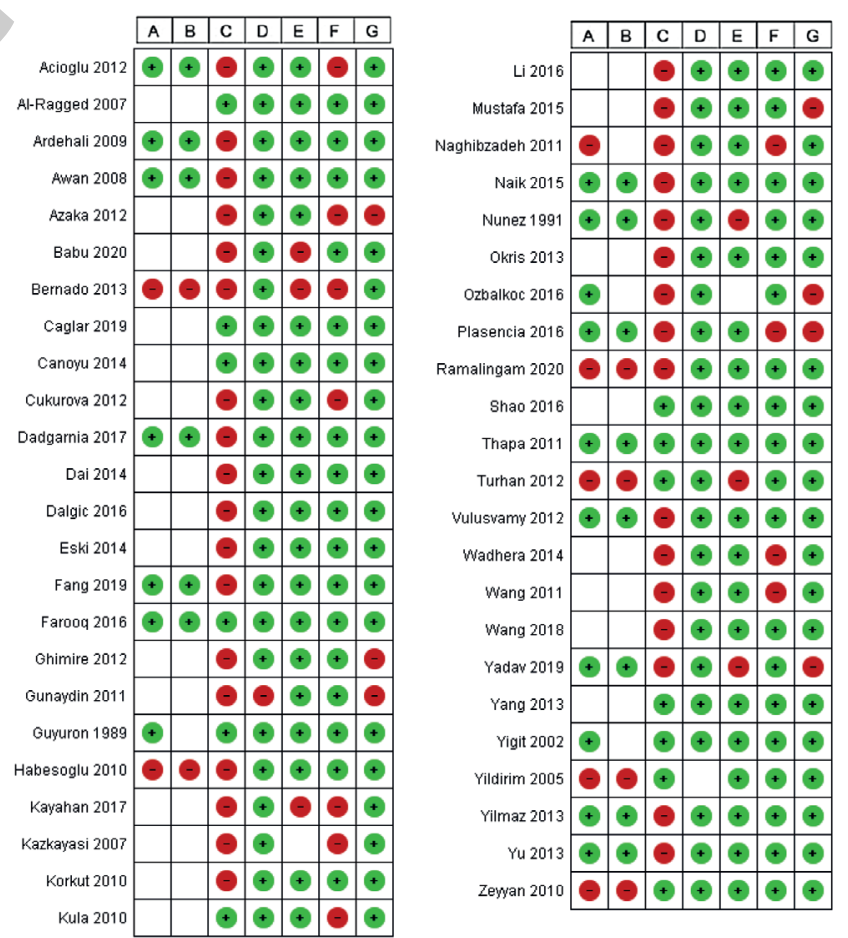

A; Random sequence generation (Selection bias), B; Allocation concealment (Selection bias), C; Blinding of participants and personnel (Performance bias), D; Blinding of outcome assessment (Detection bias), E; Incomplete outcome data (Atrition bias), F; Selective report (Reporting bias), G; Other bias

Figure 3. Methodology quality assessment for each included study. 


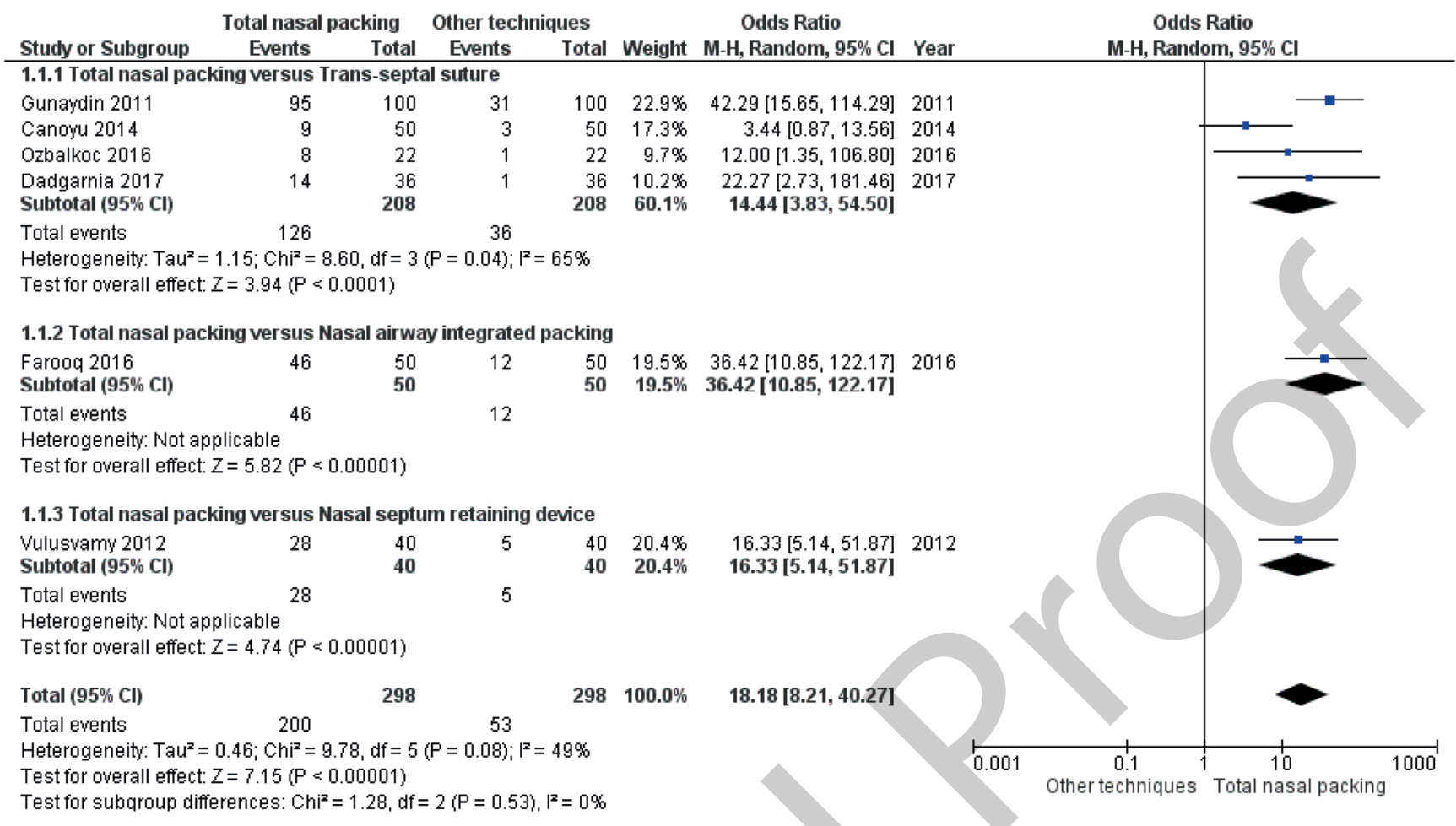

Figure 4. Respiratory distress, odds ratio (OR), Total nasal packing versus other techniques: random-effect model.

\section{Quality assessment}

Quality of the included studies was evaluated and presented in Figure 2 and Figure 3 . About $30 \%$ of the included studies had low risk of randomization and $25 \%$ had adequate concealment of allocations. Most of the studies had unclear risk of selection bias because the randomization and concealment of allocations were not mentioned in the methods. Seventy-five percent of the studies had high risk of performance bias due to lack of blinding of the participants which may influence the subjective outcomes such as sleep disturbance and pain severity. Most studies had no detection bias because the outcome measurements were not influenced by lack of blinding of the outcome assessors. Thirteen percent of the included studies had high risk of attrition bias due to a large proportion of drop-out participants without explanation. Two studies did not mention the missing data. Twenty-five percent of the included studies had reporting bias. Eight studies did not report complete statistical data of pain score. Three studies did not report numeric data of complication events, which were sleep disturbance, hematoma, and crusting. Six studies had "other bias" because these studies did not use visual analog scale (VAS) 0-10 for pain severity measurement.

\section{Characteristics of the included studies}

Forty-seven studies (4,087 participants) were included in this meta-analysis ${ }^{(9-55)}$. There were comparisons of nasal packing versus: trans-septal suture (28 studies), trans-septal suture with nasal splint (4 studies), nasal airway integrated packing (6 studies), nasal septum retaining devices (nasal clip in one study and invented nasal retaining device in one study), and inter-septal fibrin glue (1 study).The combination of nasal packing and transseptal suture was compared with trans-septal suture ( 2 studies) and the combination of nasal packing and nasal splint was compared with nasal splint (1 study). There were 3-arm intervention studies that compared nasal packing versus: 1) trans-septal suture (the second arm) and the combination of nasal packing and trans-septal suture (the third arm,1 study), 2) trans-septal suture (the second arm) and nasal airway integrated packing (the third arm,1 study), 3) nasal splint (the second arm) and nasal airway integrated packing (the third arm, 1 study). Forty studies were published in English and 7 studies were published in other languages which were Chinese, and Turkish. Forty-five studies were conducted in adult and 2 studies did not mention the age of participants. Characteristics of the included studies are shown in Table 1.

\section{Effects of interventions}

A summary of post-operative complications of nasal packing compared with other techniques is presented in Table 2 .

\section{Respiratory distress}

Six studies (596 participants) were included in this analysis. The total nasal packing significantly increased the odds of respiratory distress events compared to other procedures (OR 18.18; 


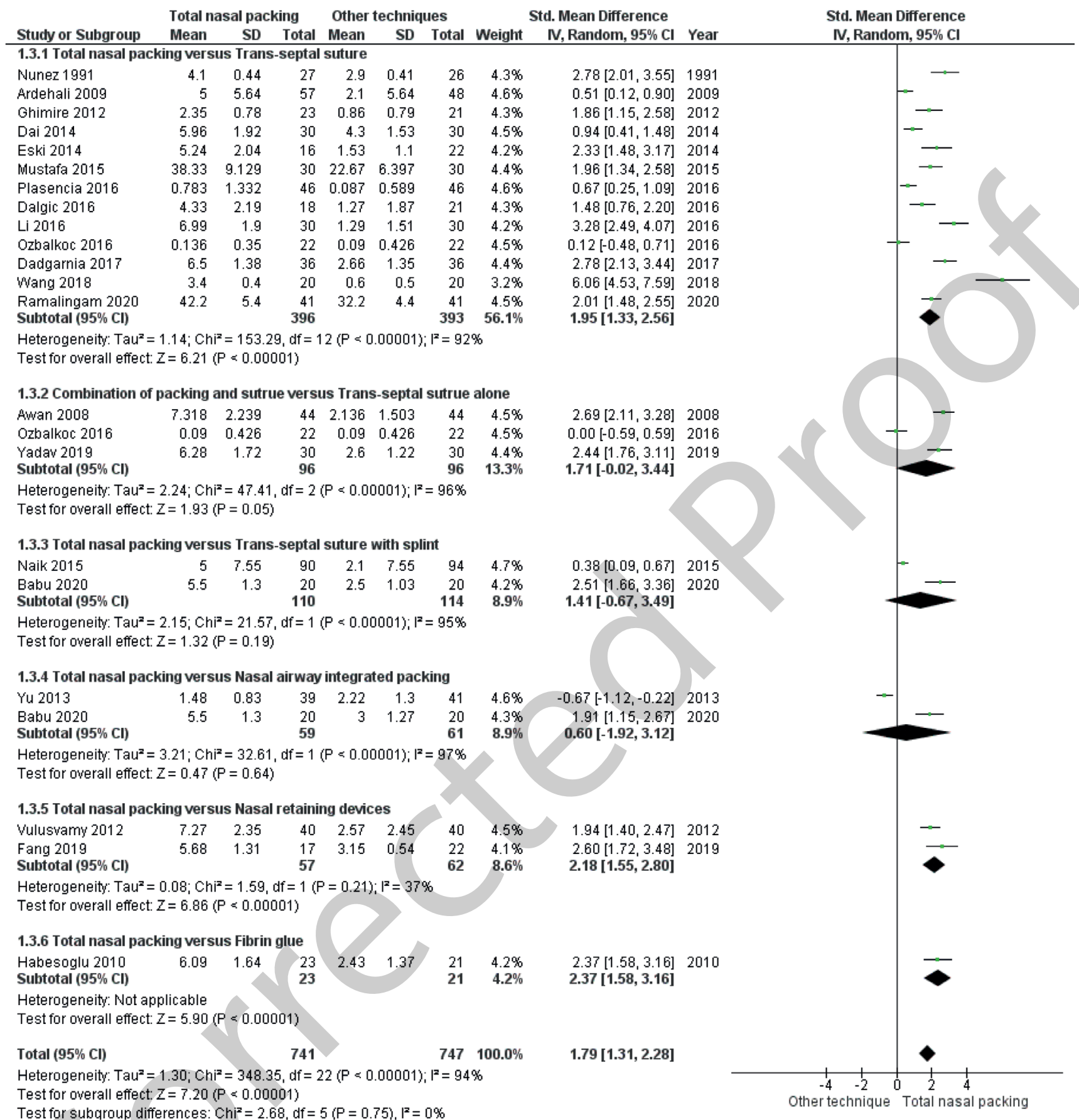

Figure 5. Pain score, Standardized mean difference (SMD), Total nasal packing versus other techniques: random-effect model.

95\% Cl 8.21-40.27; $\mathrm{p}<0.001)$. The heterogeneity was moderate (I2 = 49\%; $p=0.08)$. The results are shown in Table 2 and Figure 4. The definition of respiratory distress was different among these six studies. A summary of respiratory distress definition among the included studies is presented in Table 3.

\section{Oxygen desaturation}

Six studies (319 participants) were included in this analysis. There was no statistically significant difference between the total nasal packing and other procedures (MD $-2.01 ; 95 \% \mathrm{Cl}$ -4.03 to $0.01 ; p=0.05)$. The heterogeneity was high $(I 2=98 \% ; p$ $<0.001)$. The forest plot is shown in the electronic supplement (e-Figure 1).

\section{Pain}

Twenty-one studies (1,488 participants) were included in this analysis. The pain in the total nasal packing group was significantly worse than other procedures (SMD 1.79; 95\% Cl 1.31-2.28; 


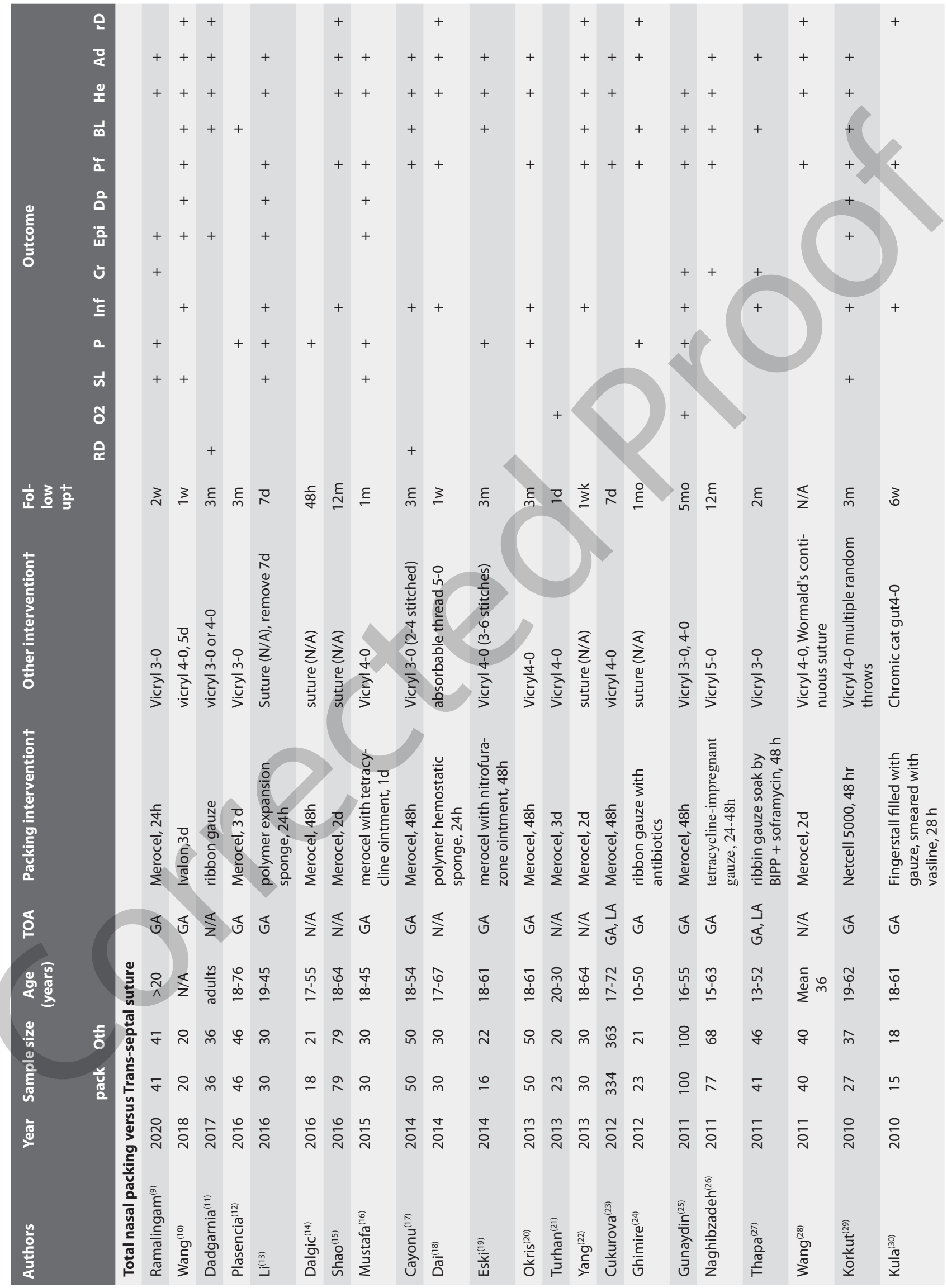



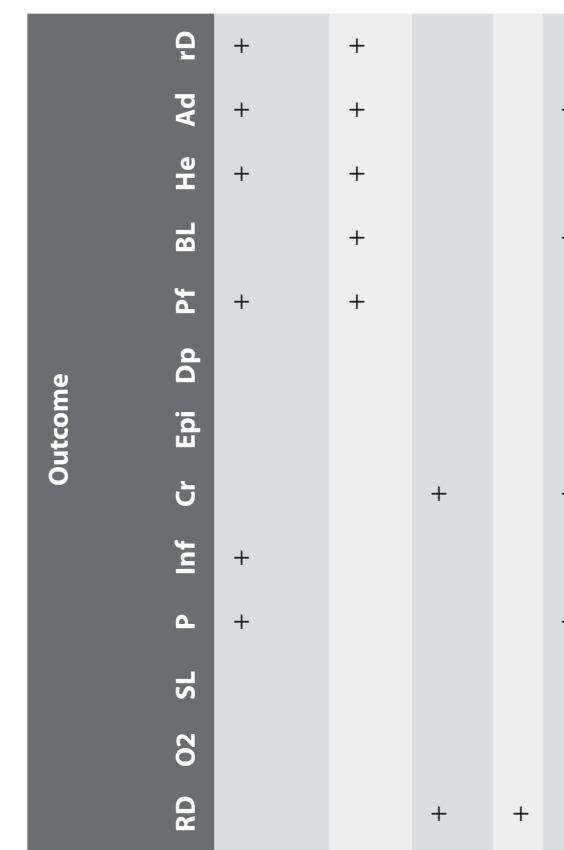

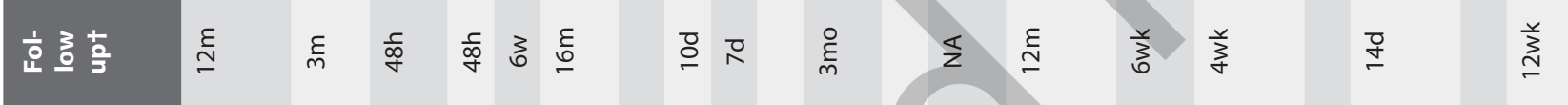

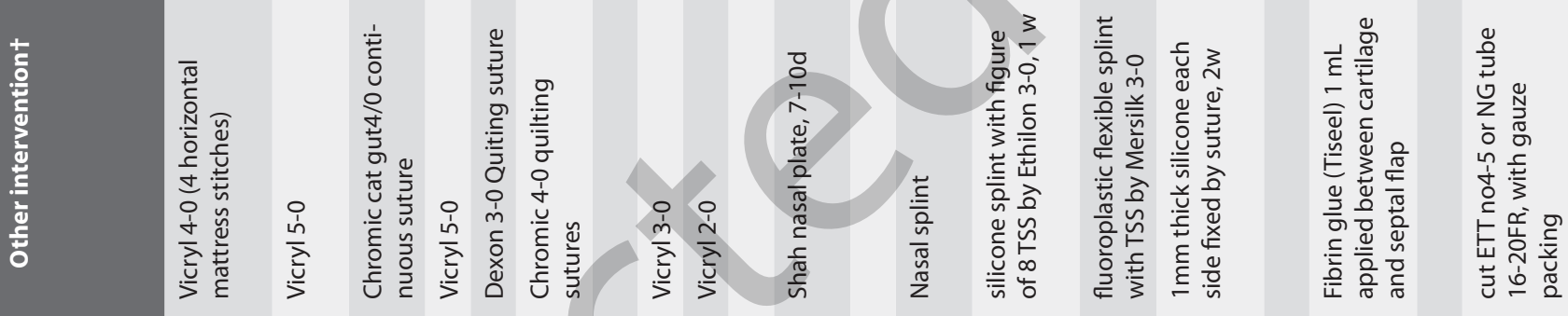

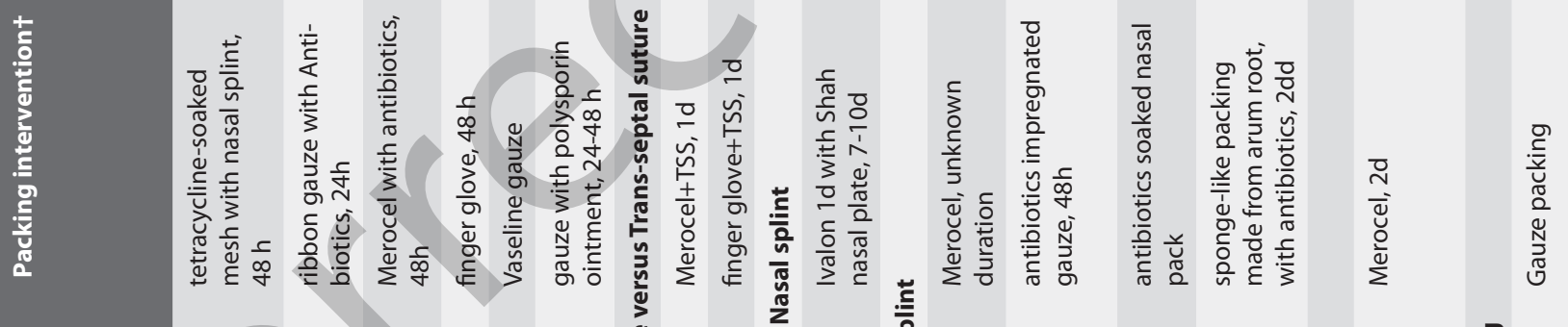

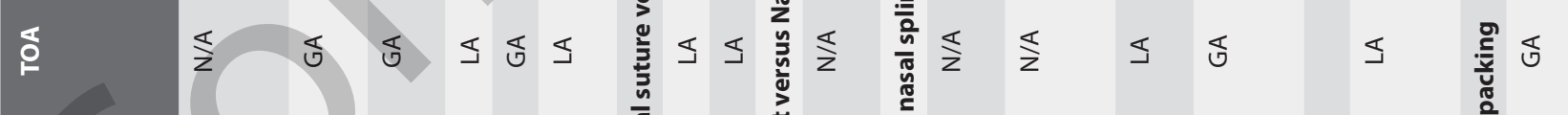

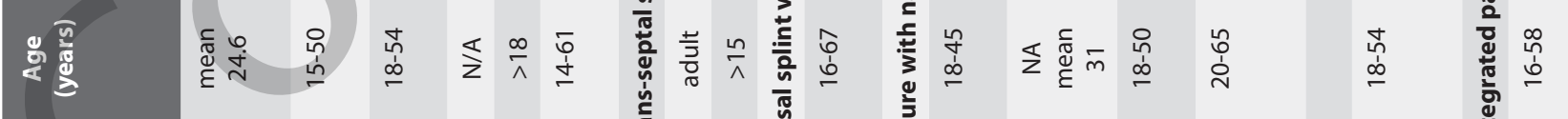
竞 $\stackrel{\infty}{>}$ $\stackrel{i}{\infty} \infty \frac{d}{\infty} \pi$ in 商

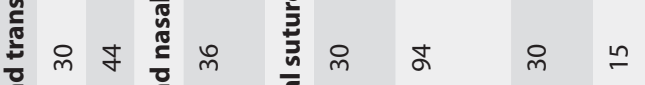




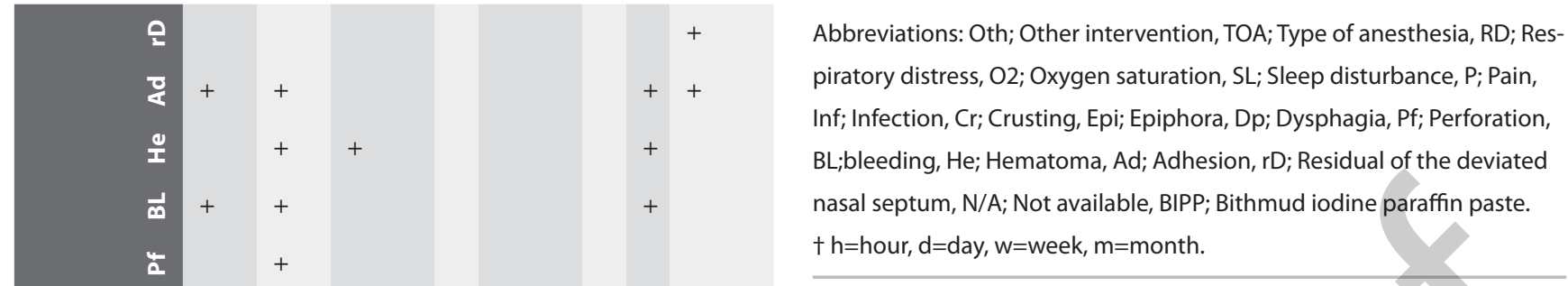

$p<0.001)$. The heterogeneity was high $(I 2=94 \% ; p<0.001)$. The result is shown in Figure 5.

\section{Bleeding}

Twenty-eight studies (2,941 participants) were included in this analysis. There was no statistically significant difference between the total nasal packing and other procedures (OR 1.23; $95 \% \mathrm{Cl}$ $0.76-1.99 ; p=0.40)$. The heterogeneity was moderate $(I 2=54 \%$; $\mathrm{P}<0.001)$. The forest plot is shown in the electronic supplement (e-Figure 2).

\section{Hematoma}

Thirty-two studies (3,355 participants) were included in this analysis. There was no statistically significant difference between the total nasal packing and other procedures (OR 2.12;95\% Cl $0.73-6.12 ; \mathrm{P}=0.17)$. The heterogeneity was moderate $(I 2=46 \%$; $\mathrm{P}=0.04)$. The forest plot is shown in the electronic supplement (e-Figure 3).

\section{Sleep disturbance}

Seven studies (501 participants) were included in this analysis. The total nasal packing significantly increased the odds of sleep disturbance events compared to other procedures (OR 11.92; $95 \% \mathrm{Cl} 4.95-28.66 ; \mathrm{P}<0.001)$. The heterogeneity was high $(12=$ $71 \% ; \mathrm{P}=0.002)$. The forest plot is shown in the electronic supplement (e-Figure 4).

\section{Infection}

Nineteen studies (1,531 participants) were included in this analysis. There was no statistically significant difference between the total nasal packing and other procedures (OR 2.21; $95 \%$ $\mathrm{Cl} 0.84-5.78 ; \mathrm{P}=0.11)$. The heterogeneity was low $(\mathrm{I} 2=0 \% ; \mathrm{P}$ $=0.57)$. The forest plot is shown in the electronic supplement (e-Figure 5).

\section{Crusting}

Eleven studies (947 participants) were included in this analysis. The total nasal packing significantly increased the odds of crusting events compared to other procedures (OR 4.26; $95 \% \mathrm{CI}$ 1.70-10.69; $P=0.002)$. The heterogeneity was high $(I 2=70 \% ; P$ $<0.001)$. The forest plot is shown in the electronic supplement (e-Figure 6). 
Table 2. A summary of post-operative complications of the total nasal packing, comparing to other alternatives techniques.

\begin{tabular}{|llccccccc|}
\hline Outcome & Studies & Participants & $\begin{array}{c}\text { Statistical } \\
\text { methods }\end{array}$ & Effect & $95 \% \mathbf{C l}$ & $\begin{array}{c}\text { p-value } \\
\text { I2 } \\
\text { (p-value) }\end{array}$ \\
\hline 1 & Respiratory distress & 6 & 596 & OR (RE) & 18.18 & $8.21,40.27$ & $<0.001$ & $49 \%(0.008)$ \\
\hline 2 & Oxygen saturation & 6 & 319 & MD (RE) & -2.01 & $-4.03,0.01$ & 0.05 & $98 \%(<0.001)$ \\
\hline 3 & pain severity & 21 & 1,488 & SMD (RE) & 1.79 & $1.31,2.28$ & $<0.001$ & $94 \%(<0.001)$ \\
\hline 4 & Bleeding & 28 & 2,941 & OR (RE) & 1.23 & $0.76,1.99$ & 0.40 & $54 \%(0.001)$ \\
\hline 5 & Hematoma & 32 & 3,355 & OR (RE) & 2.12 & $0.73,6.12$ & 0.17 & $46 \%(0.04)$ \\
\hline 6 & Sleep disturbance & 7 & 501 & OR (RE) & 11.92 & $4.95,28.66$ & $<0.001$ & $71 \%(0.002)$ \\
\hline 7 & Infection & 19 & 1,513 & OR (FE) & 2.21 & $0.84,5.78$ & 0.11 & $0 \%(0.57)$ \\
\hline 8 & Crusting & 11 & 937 & OR (RE) & 4.26 & $1.70,10.69$ & 0.002 & $70 \%(<0.001)$ \\
\hline 9 & Epiphora & 9 & 657 & OR (RE) & 65.91 & $12.87,337.42$ & $<0.001$ & $81 \%(<0.001)$ \\
\hline 10 & Dysphagia & 6 & 452 & OR (RE) & 59.78 & $5.52,647.53$ & $<0.001$ & $91 \%(<0.001)$ \\
\hline 11 & Perforation & 21 & 2,394 & OR (FE) & 1.67 & $0.87,3.19$ & 0.12 & $0 \%(0.99)$ \\
\hline 12 & Adhesion & 32 & 3,003 & OR (FE) & 2.40 & $1.64,3.51$ & $<0.001$ & $0 \%(0.65)$ \\
\hline 13 & residual DNS & 13 & 1,118 & OR (FE) & 0.93 & $0.59,1.49$ & 0.78 & $26 \%(0.22)$ \\
\hline
\end{tabular}

OR; Odd ratio, MD; Mean difference, SMD; Standardized mean difference, RE; Random effect model, FE; Fixed effect model DNS; deviation of nasal septum.

Table 3. A summary of respiratory distress definition among the included studies.

\begin{tabular}{|c|c|}
\hline $\begin{array}{l}\text { Study (author, year, } \\
\text { reference number) }\end{array}$ & Respiratory distress definition \\
\hline Gunaydin $2011^{(25)}$ & $\begin{array}{l}\text { Extubation difficulty score }>1 \text {. } \\
\text { Extubation was scored, based on the amount of secretion, the occurrence of laryngospasm, the need for oropharyngeal } \\
\text { airway usage, and the effort of nasal breathing by an anesthesiologist. } \\
\text { The score was in 0-4 scale: } 0 \text { easiest, } 1 \text { easy, } 2 \text { moderately difficult, } 3 \text { difficult, } 4 \text { most difficult. }\end{array}$ \\
\hline Cayonu $2014^{(17)}$ & $\begin{array}{l}\text { Respiratory events related to anesthesia in the operating theatre, defined as any unanticipated } \\
\text { - } \quad \text { hypoxemia (hemoglobin oxygen saturation }<90 \% \text { ) } \\
\text { - } \quad \text { hypoventilation (respiratory rate }<8 \text { breaths/min or arterial carbon dioxide tension }>50 \mathrm{mmHg} \text { ) } \\
\text { upper airway obstruction (stridor or laryngospasm) requiring an active and specific intervention (ventilation, } \\
\text { tracheal intubation, opioid or muscle relaxant antagonism, insertion of oral/nasal airway or airway manipulation) }\end{array}$ \\
\hline Ozbalkoc $2016^{(54)}$ & $\begin{array}{l}\text { Anesthesia related parameters: Difficulty at extubation. Of note, this study also recorded other anesthesia related } \\
\text { parameters which were not included in the forest plot (presence of laryngospasm after surgery, need for oropharyngeal } \\
\text { airway, effort for nasal respiration) }\end{array}$ \\
\hline Dadgarnia $2017^{(11)}$ & Presence of dyspnea symptoms in the first 48 hours after surgery, complaint by the patient \\
\hline Faroog $2016^{(45)}$ & Presence of difficult recovery from general anesthesia, including unsmooth or late recovery considered by doctors \\
\hline Vulsvamy $2012^{(52)}$ & $\begin{array}{l}\text { Average oxygen saturation }<95 \% \text { from the } 6 \text {-hour record of post-operative continuous oxygen saturation (SpO2) moni- } \\
\text { toring, every } 30 \text { minutes. }\end{array}$ \\
\hline
\end{tabular}

\section{Epiphora}

Nine studies (657 participants) were included in this analysis.

The total nasal packing significantly increased the odds of epiphora events compared to other procedures (OR 65.91; $95 \% \mathrm{Cl}$ 12.87-337.42; $\mathrm{P}<0.001)$. The heterogeneity was high ( $12=81 \%$; $\mathrm{P}<0.001)$. The forest plot is shown in the electronic supplement (e-Figure 7).

\section{Dysphagia}

Six studies (452 participants) were included in this analysis. The total nasal packing significantly increased the odds of dyspha- gia events compared to other procedures (OR 59.78; $95 \% \mathrm{Cl}$ 5.52-647.53; $\mathrm{P}<0.001)$. The heterogeneity was high ( $12=91 \%$; $\mathrm{P}$ $<0.001)$. The forest plot is shown in the electronic supplement (e-Figure 8).

\section{Perforation}

Twenty-one studies (2,394 participants) were included in this analysis. There was no statistically significant difference between the total nasal packing and other procedures (OR 1.67; 95\% $\mathrm{Cl} 0.87-3.19 ; \mathrm{P}=0.12)$. The heterogeneity was low $(12=0 \% ; \mathrm{P}$ $=0.99$ ). The forest plot is shown in the electronic supplement 
(e-Figure 9).

\section{Adhesion}

Thirty-two studies (3,003 participants) were included in this analysis. The total nasal packing significantly increased the odds of adhesion events compared to other procedures (OR 2.40; 95\% $\mathrm{Cl} 1.64-3.51 ; \mathrm{P}<0.001)$. The heterogeneity was low $(I 2=0 \% ; \mathrm{P}=$ 0.65). The result is shown in Figure 6.

\section{Residual deviation of the nasal septum}

Thirty studies (1,118 participants) were included in this analysis There was no statistically significant difference between the total nasal packing and other procedures (OR 0.93; $95 \% \mathrm{CI}$ 0.59-1.49; $\mathrm{P}=0.78)$. The heterogeneity was low $(\mathrm{I} 2=26 \% ; \mathrm{P}=$ 0.22 ) The forest plot is shown in the electronic supplement (eFigure 10).

\section{Subgroup analysis by the techniques \\ Total nasal packing versus trans-septal suture}

There were 30 studies comparing postoperative complications between total nasal packing and trans-septal suture. The results favored the trans-septal suture over the nasal packing, for decreasing respiratory distress, pain, sleep disturbance, crusting, epiphora, dysphagia, and adhesion. There were no significant differences in oxygen saturation, bleeding, hematoma, infection, perforation, and residual deviation of the nasal septum. A summary of postoperative complications between nasal packing and trans-septal suture is presented in the electronic supplement (e-Table 1).

Combination of nasal packing and trans-septal suture versus transseptal suture alone

There were 3 studies comparing the nasal packing and transseptal suture combination versus trans-septal suture alone. The sleep disturbance, epiphora, and dysphagia were significantly higher in the combination technique. There were no significant differences in pain severity, infection, bleeding, and hematoma. Other outcomes could not be analyzed due to insufficient number of studies.

Total nasal packing versus trans-septal suture with nasal splint There were 5 studies comparing total nasal packing versus trans-septal suture with splint. The crusting was worsened in the total nasal packing. There were no significant differences in pain severity, bleeding, hematoma, perforation, and adhesion. Other outcomes could not be analyzed due to insufficient number of studies.

\section{Total nasal packing versus nasal airway integrated packing}

There were 8 studies comparing total nasal packing versus nasal airway integrated packing. However, there was only 1 study for each of the following outcomes that statistically favored the nasal airway integrated packing: respiratory distress, sleep disturbance, and epiphora. There were no statistical differences in oxygen saturation, pain severity, infection, dysphagia, perforation, bleeding, hematoma, and adhesion. None of the studies compared the residual deviated nasal septum.

\section{Combination of nasal packing and nasal splint, nasal retaining devices, and fibrin glue}

There was an insufficient number of the studies for each analysis.

\section{Sensitivity analysis}

We performed a sensitivity analysis based on methodological characteristics. The analysis of high-quality studies showed a consistency of results in most of the outcomes. The number of high-quality studies in crusting were too few to perform a sensitivity analysis. Some outcomes of the meta-analysis had significant heterogeneities. Therefore, a sensitivity analysis of these outcomes was performed by excluding the studies that contributed the most to the 12. The sensitivity analyses after excluding the outliers showed consistent results.

Different types of pain score were used among the studies to assess the pain severity outcome. The most frequently used was visual analog scale (VAS), the score ranged from 0 to 10. The sensitivity analysis was performed in the studies that used the VAS $0-10$. We found that the mean difference of VAS in nasal packing group was higher than other techniques by 3 points. Results are shown in the electronic supplement (e-Figure 11).

\section{Publication bias}

The funnel plots of most outcomes revealed that the distribution of the studies was reasonably symmetrical which suggested no evidence of publication bias. However, the funnel plots of epiphora and dysphagia events revealed asymmetrical distribution which suggested the publication bias. The funnel plots are shown in the electronic supplement (e-Figure 12).

\section{Discussion}

The results of this meta-analysis demonstrated that nasal packing after septoplasty was more likely to cause adverse events, including respiratory distress, pain, sleep disturbance, crusting, epiphora, dysphagia, and adhesion. Nasal packing did not show benefits in preventing bleeding, hematoma, and residual nasal septum deviation when compared with other techniques. Subgroup analyses results favored the trans-septal suture over the nasal packing, for decreasing respiratory distress, pain, sleep disturbance, crusting, epiphora, dysphagia, and adhesion. There were no significant differences in oxygen desaturation, infection, septal perforation, bleeding, hematoma, and residual nasal septum deviation. Adding nasal packing to trans-septal suture 
increased sleep disturbance, epiphora, and dysphagia but did not decrease bleeding and hematoma. Trans-septal suture with splint had benefit over nasal packing only in decreasing the crust but no significant differences in other outcomes. There were insufficient randomized control studies of other techniques, including the nasal airway integrated packing, nasal retaining devices, and fibrin glue, for the subgroup analyses. In-line with the previous meta-analyses ${ }^{(4-7)}$, the results of this study did not find any significant differences between the nasal packing and trans-septal suture in bleeding, hematoma, perforation, and residual septal deviation. Our study also found that the trans-septal suture had a significant advantage over the nasal packing in decreasing post-operative pain. The analysis of adhesion outcome is consistent with the previous meta-analyses by Kim et al. and Wang et al. ${ }^{(6,7)}$, which concluded that the nasal packing had a higher adhesion rate than trans-septal suture. However, the other meta-analyses by Banglawala (2013) et al. and Certal et al. ${ }^{(4,5)}$ did not find a significant difference in adhesion rate. There was no difference in infection rate which is consistent with the previous meta-analyses ${ }^{(5-7)}$. A meta-analysis performed by Banglawala (2014) et al. ${ }^{(8)}$ did not find significant oxygen desaturation caused by nasal packing, which is consistent with our study. However, we found that nasal packing caused respiratory distress which is more important than desaturation due to the possibility of causing serious consequences.

The safety of nasal packing after septoplasty should be strongly considered because this meta-analysis showed both statistically and clinically significant increases in adverse events (respiratory distress, sleep disturbance, crusting, epiphora, dysphagia, and adhesion) when compare to other techniques. In addition, the sensitivity analysis of pain score showed an increase in VAS by 3 out of the 10-point pain score. Furthermore, it did not have advantages over other techniques in the prevention of bleeding, hematoma, and residual septal deviation. As for clinical implications, this meta-analysis suggested that routine nasal packing after septoplasty should be avoided since it could cause adverse events, especially respiratory distress. The technique with sufficient evidence that can be used as an alternative to the nasal packing is trans-septal suture. Future research with welldesigned RCTs, comparing other techniques to the trans-septal suture should be performed.

This is the first meta-analysis that assessed respiratory distress, sleep disturbance, crusting, epiphora, and dysphagia in addition to other outcomes. The alternative techniques other than trans- septal suture were also included in this meta-analysis. Moreover, our analysis also included the primary studies that were not published in English. The limitations of our study included the measurements of the primary outcome that were different among the studies; for example, the definition of respiratory distress event was different in each included study and most of them were subjective outcomes reported by either anesthesiologists or patients. Nevertheless, we thought that those events could be pooled as the respiratory distress event, because they were all unwanted adverse outcomes that could cause serious consequences. The low quality of the included studies was another limitation, such as the studies with no explanations about the randomization and allocation concealment. Most of the included studies had high risk of performance bias. The postoperative procedure could not be blinded; therefore, we had to be cautious since it could influence the subjective outcomes. In addition, the funnel plots showed publication bias in epiphora and dysphagia. The high heterogeneity of the included studies was due to the data being pooled from studies with different surgical techniques, anesthetic techniques and outcome measurement tools. We accepted the inherent heterogeneity and used a random-effects model for analysis and performed a sensitivity analysis by excluding the outliers that caused the most heterogeneity. The sensitivity analysis showed a consistency of results. Further well-designed research should be performed regarding these limitations.

\section{Acknowledgements}

Thank you to the Research affairs, Faculty of medicine, Chulalongkorn university for English language editing and medical writer service.

\section{Authorship contribution}

CKT, PH: designed the concept. CKT, NC, BC: performed data searching, study selection, quality assessment. $\mathrm{PH}$ : resolved the discrepancies. CKT, NC: extracted data. CKT: analyzed data. CKT, $\mathrm{PH}$ : interpreted data. CKT, drafted the article. NC, BC, PH: provided the feedback, revised the article. CKT: wrote manuscript, sent for English language editing. CKT, PH: approved the final version of manuscript.

\section{Conflict of interest}

None.

\section{References}

1. Flint PW, Haughey BH, Lund VJ, et al. Cummings Otolaryngology: Head and Neck Surgery, 3-Volume Set: Elsevier; 2020.

2. Hari C, Marnane C, Wormald PJ. Quilting sutures for nasal septum. J Laryngol Otol.
2008;122(5):522-3

3. Weber R, Hochapfel F, Draf W. Packing and stents in endonasal surgery. Rhinology. 2000;38(2):49-62.

4. Banglawala SM, Gill M, Sommer DD, Psaltis A, Schlosser R, Gupta M. Is nasal packing necessary after septoplasty? A meta-analysis. Int Forum Allergy Rhinol. 2013;3(5):41824.

5. Certal V, Silva H, Santos T, Correia A, Carvalho C. Trans-septal suturing technique in septoplasty: a systematic review and 
meta-analysis. Rhinology. 2012;50(3):236-45

6. Kim JS, Kwon SH. Is nonabsorbable nasal packing after septoplasty essential? A metaanalysis. Laryngoscope. 2017;127(5):102631.

7. Wang WW, Dong BC. Comparison on effectiveness of trans-septal suturing versus nasal packing after septoplasty: a systematic review and meta-analysis. European Arch Oto-rhino-laryngol. 2017;274(11):3915-25.

8. Banglawala SM, Gill MS, Dhillion N, Khan JS, Gupta MK, Psaltis A, et al. Nasal packing after septoplasty: cardiopulmonary impact. JAMA Otolaryngol Head Neck Surg. 2014;140(3):253-8.

9. Ramalingam $V$, Venkatesan $R$, Somasundaram S, Kandasamy K, Rajeswari M. A Comparative Study Between Septal Quilting Sutures Without Nasal Packing and Only Nasal Packing Post-septal Correction. Indian J Otolaryngol Head Neck Surg. 2020;72(2):169-74.

10. Wang HD, Song PP, Hou J, et al. [Clinical significance of continuous transfixion suture for nasal septum in septoplasty]. Lin chuang er bi yan hou tou jing wai ke za zhi = J Clin Otorhinolaryngol Head Neck Surg. 2018;32(12):927-30

11. Dadgarnia M, Meybodian M, Karbasi A, et al. Comparing nasal packing with transseptal suturing following septoplasty: a randomized clinical trial. Eur Arch Oto-rhinolaryngol. 2017;274(9):3513-8.

12. Plasencia DP, Falcón JC, Barreiro SB, Bocanegra-Pérez MS, Barrero MV, Macías Á R. Transeptal suturing - a cost-efficient alternative for nasal packing in septal surgery. Braz J Otorhinolaryngol. 2016;82(3):310-3.

13. Li D, Wang W, Lin Y. [Application of continuous sutures for nasal septum after septoplasty]. Lin chuang er bi yan hou tou jing wai ke za zhi $=$ J Clin Otorhinolaryngol Head Neck Surg. 2016;30(5):381-2.

14. Dalgic A, Is A, Dinc ME, Ulusoy S, Avinçsal M, Kulekci M. The Effects of Nasal Packing and Transseptal Suturing After Septoplasty on Olfactory Function, Patient Comfort, and Mucociliary Clearance. J Craniofacial Surg. 2016;27(5):e487-90

15. Shao Y, Zhao R, Li H. Treatment effect of continuous suture technique for nasal septum after septoplasty. Chin Arch Otolaryngol Head Neck Surg. 2015; 23: 599601.

16. Mustafa S, Abdulrazzaq AF. Effect of transseptal suture technique versus nasal packing after septoplasty. Int J Tech Res Appl. 2015; 3(4): 33-40.

17. Cayonu M, Acar A, Horasanlı E, Altundag A, Salihoglu M. Comparison of totally occlusive nasal pack, internal nasal splint, and transseptal suture technique after septoplasty in terms of immediate respiratory distress related to anesthesia and surgical complications. Acta Otolaryngol. 2014:134(4):390-4

18. Dai B, Liu W, Jin A, Jiang $X$, Feng L. [Efficacy of nasal packing, septal suture technique and vacuum sealing drainage after nasal septum surgery]. Lin chuang er bi yan hou tou jing wai ke za zhi $=$ J Clin Otorhinolaryngol Head Neck Surg. 2014;28(2):118-21.

19. Eşki E, Güvenç IA, Hızal E, Yılmaz I. Effects of nasal pack use on surgical success in septoplasty. Kulak burun bogaz ihtisas dergisi KBB $=J$ ENT 2014;24(4):206-10.

20. Özkırıs M, Kapusuz Z, Saydam L. Comparison of nasal packs with transseptal suturing after nasal septal surgery. Am J Otolaryngol. 2013;34(4):308-11.

21. Turhan M, Bostancı A, Akdag M, Dinc O. A comparison of the effects of packing or transseptal suture on polysomnographic parameters in septoplasty. Eur Arch Otorhino-laryngol. 2013;270(4):1339-44

22. Yang $M B$, Zhang $Y H$, Xia $X L$, Qiu $S Q$, Zhao $H L$, Lan JP. Skill of continuous sutures for nasal septum after septoplasty. Chin Arch Otolaryngol Head Neck Surg. 2013; 20: 349-52.

23. Cukurova I, Cetinkaya EA, Mercan GC Demirhan E, Gumussoy M. Retrospective analysis of 697 septoplasty surgery cases: packing versus trans-septal suturing method. Acta Otorhinolaryngol Ital. 2012;32(2):111-4

24. Ghimire A, Limbu TR, Bhandari R. Trans septal suturing following septoplasty: an alternative for nasal packing. Nepal Med Coll J. 2012;14(3):165-8.

25. Günaydın R, Aygenc E, Karakullukcu S, Fidan F. Celikkanat S. Nasal packing and transseptal suturing techniques: surgical and anaesthetic perspectives. Eur Arch Oto-rhinolaryngol. 2011;268(8):1151-6.

26. Naghibzadeh B, Peyvandi AA, Naghibzadeh G. Does post septoplasty nasal packing reduce complications? Acta medica Iranica. 2011;49(1):9-12

27. Thapa N, Pradhan B. Postoperative complications of septal quilting and BIPP packing following septoplasty. J Nepal Health Res Counc. 2011:9(2):186-8

28. Wang $M$, Xing $Z$, Yuan $X$, Liu Y, Han L, Qin N. [Effect of nasal septal suture versus nasal packing after septoplasty]. Lin chuang er bi yan hou tou jing wai ke za zhi $=\mathrm{J}$ Clin Otorhinolaryngol Head Neck Surg. 2011;25(23):1068-70, 75

29. Korkut AY, Teker AM, Eren SB, Gedikl $\mathrm{O}$, Askiner $\mathrm{O}$. A randomised prospective trial of trans-septal suturing using a nove device versus nasal packing for septoplasty. Rhinology. 2010;48(2):179-82.

30. Kula M, Yuce I, Unlu Y, Tutus A, Cagli S, Ketenci I. Effect of nasal packing and haemostatic septal suture on mucociliary activity after septoplasty: an assessment by rhinoscintigraphy. Eur Arch Oto-rhinolaryngol. 2010;267(4):541-6

31. Ardehali MM, Bastaninejad S. Use of nasal packs and intranasal septal splints following septoplasty. Int J Oral Maxillofac Surg. 2009;38(10):1022-4

32. Al-Raggad DK, El-Jundi AM, Al-Momani OS et al. Suturing of the nasal septum after septoplasty, is it an effective alternative to nasal packing? Saudi medical journal. 2007;28(10):1534-6

33. Kazkayasi M, Dinçer C, Arikan OK, Kiliç R. [The effect of nasal packing and suture technique on systemic oxygen saturation and patient comfort after septoplasty]. Kulak burun bogaz ihtisas dergisi : $\mathrm{KBB}=\mathrm{J}$ ENT. 2007:17(6):318-23.

34. Yildirim A, Yasar M, Bebek Al, Canbay E, Kunt T. Nasal septal suture technique versus nasal packing after septoplasty. Am J Rhinol. 2005;19(6):599-602.

35. Nunez DA, Martin FW. An evaluation of post-operative packing in nasal septal surgery. Clin Otolaryngol Allied Sci. 1991;16(6):549-50.

36. Guyuron B. Is packing after septorhinoplasty necessary? A randomized study. Plast Reconstr Surg. 1989;84(1):41-4; discussion 5-6.

37. Yadav K, Ojha T, Gakhar S, Sharma A, Singhal A, Kataria V. Effectiveness of Nasal Packing in Trans-septal Suturing Technique in Septoplasty: A Randomized Comparative Study. Indian J Otolaryngol Head Neck Surg. 2019;71(Suppl 3):1765-9.

38. Awan MS, lqbal M. Nasal packing after septoplasty: a randomized comparison of packing versus no packing in 88 patients. ENT J. 2008;87(11):624-7

39. Bernardo MT, Alves S, Lima NB, Helena D, Condé A. Septoplasty with or without postoperative nasal packing? Prospective study. Braz J Otorhinolaryngol. 2013;79(4):471-4.

40. Caglar O, Guclu O, Oymak S, Derekoy S. The Effects of Different Types of Nasal Packing on Odor Function and Mucociliary Function After Septum Surgery. ENT J. 2019;98(8):486-9.

41. Naik K. A novel way of trans-septal splint suturing without nasal packing for septoplasty. Indian J Otolaryngol Head Neck Surg. 2015;67(1):48-50

42. Wadhera R, Zafar N, Gulati SP, Kalra V, Ghai A. Comparative study of intranasal septal splints and nasal packs in patients undergoing nasal septal surgery. ENT J. 2014:93(9):396-408

43. Asaka D, Yoshikawa M, Okushi T, Nakayama T, Matsuwaki Y, Otori N, et al. Nasal splinting using silicone plates without gauze packing following septoplasty combined with inferior turbinate surgery. Auris, nasus, larynx. 2012:39(1):53-8.

44. Habesoglu TE, Kulekci S, Habesoglu M, Deveci I, Deveci S, Toros S, et al. Comparative outcomes of using fibrin glue in septoplasty and its effect on mucociliary activity. Otolaryngol Head Neck Surg 2010;142(3):394-9.

45. Farooq M, editor Ventilating Anterior Nasal Packing after Septoplasty 2016.

46. Yilmaz MS, Guven M, Elicora SS, Kaymaz R. An evaluation of biodegradable synthetic polyurethane foam in patients following septoplasty: a prospective rand- 
omized trial. Otolaryngol Head Neck Surg. 2013;148(1):140-4.

47. Yu SS, Mei KD, Lin YS. Does airway integrated nasal packing after septal surgery improve body oxygenation? Rhinology. 2013;51(3):243-8.

48. Acıoğlu E, Edizer DT, Yiğit Ö, Onur F, Alkan Z. Nasal septal packing: which one? Eur Arch Otorhinolaryngol. 2012;269(7):1777-81.

49. Zayyan E, Bajin MD, Aytemir K, YIImaz T. The effects on cardiac functions and arterial blood gases of totally occluding nasal packs and nasal packs with airway. Laryngoscope. 2010;120(11):2325-30.

50. Yiğit O, Cinar U, Uslu B, Akgül G, Topuz E, Dadaş B. [The effect of nasal packing with or without an airway on arterial blood gases during sleep]. Kulak burun bogaz intisas dergisi : KBB = J ENT 2002;9(5):347-50.

51. Fang S, Wei X, Ying L, Zhu L, Cui J, Ma Z, et al. Comparative study of nasal septal retainer and nasal packing in patients undergo- ing septoplasty. Eur Arch Otorhinolaryngol. 2019;276(8):2251-7.

52. Veluswamy A, Handa S, Shivaswamy S. Nasal septal clips: an alternative to nasal packing after septal surgery? Indian J Otolaryngol Head Neck Surg. 2012;64(4):346-50.

53. Kayahan B, Ozer S, Suslu AE, Ogretmenoglu $\mathrm{O}$, Onerci M. The comparison of the quality of life and intranasal edema between the patients with or without nasal packing after septoplasty. Eur Arch Otorhinolaryngol. 2017;274(3):1551-5.

54. Özbal Koç AE, Türkoğlu Babakurban S, Kibar SS, Büyüklü F. A comparative study on nasal packing after septoplasty: does it matter in terms of patient comfort, bleeding, and crust or synechia formation? Kulak burun bogaz intisas dergisi : KBB $=J$ ENT. 2016;26(3):152-8.

55. Babu AR, Shankar De K, Prakash BG, Sreenivas Kamath K. Quest for the Ideal Nasal Pack in Post Operative Cases of Septo-
Turbinoplasty: Study in a Tertiary Care Hospital. Indian J Otolaryngol Head Neck Surg. 2020;72(4):463-7.

Chernkwan K. Titirungruang, MD

Department of Otolaryngology

Faculty of Medicine

Chulalongkorn University

1873, Rama 4 rd.

Bangkok, 10330

Thailand

E-mail: c.titirungruang@gmail.com 


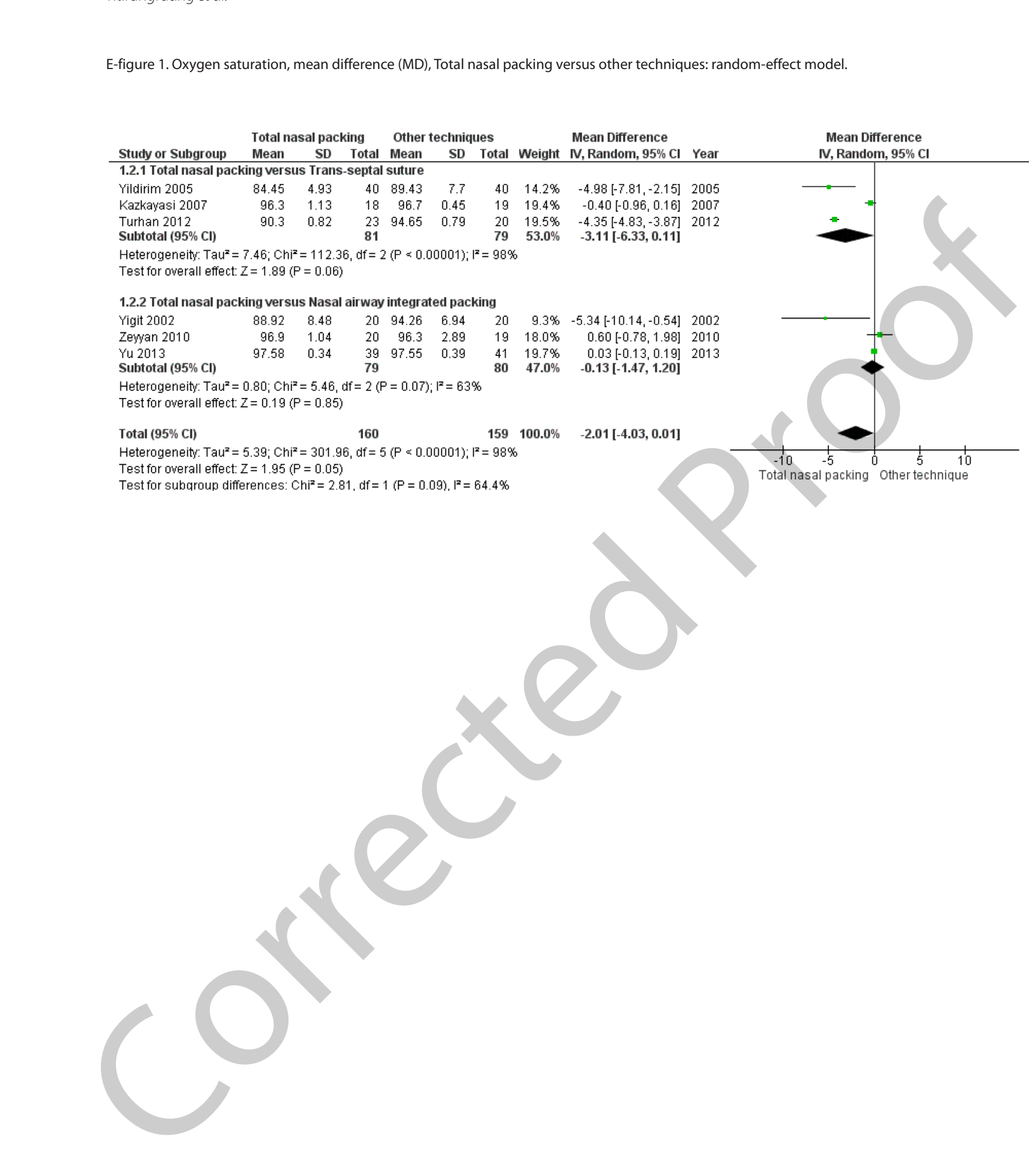


E-figure 2. Bleeding, odds ratio (OR), Total nasal packing versus other techniques: random-effect model.

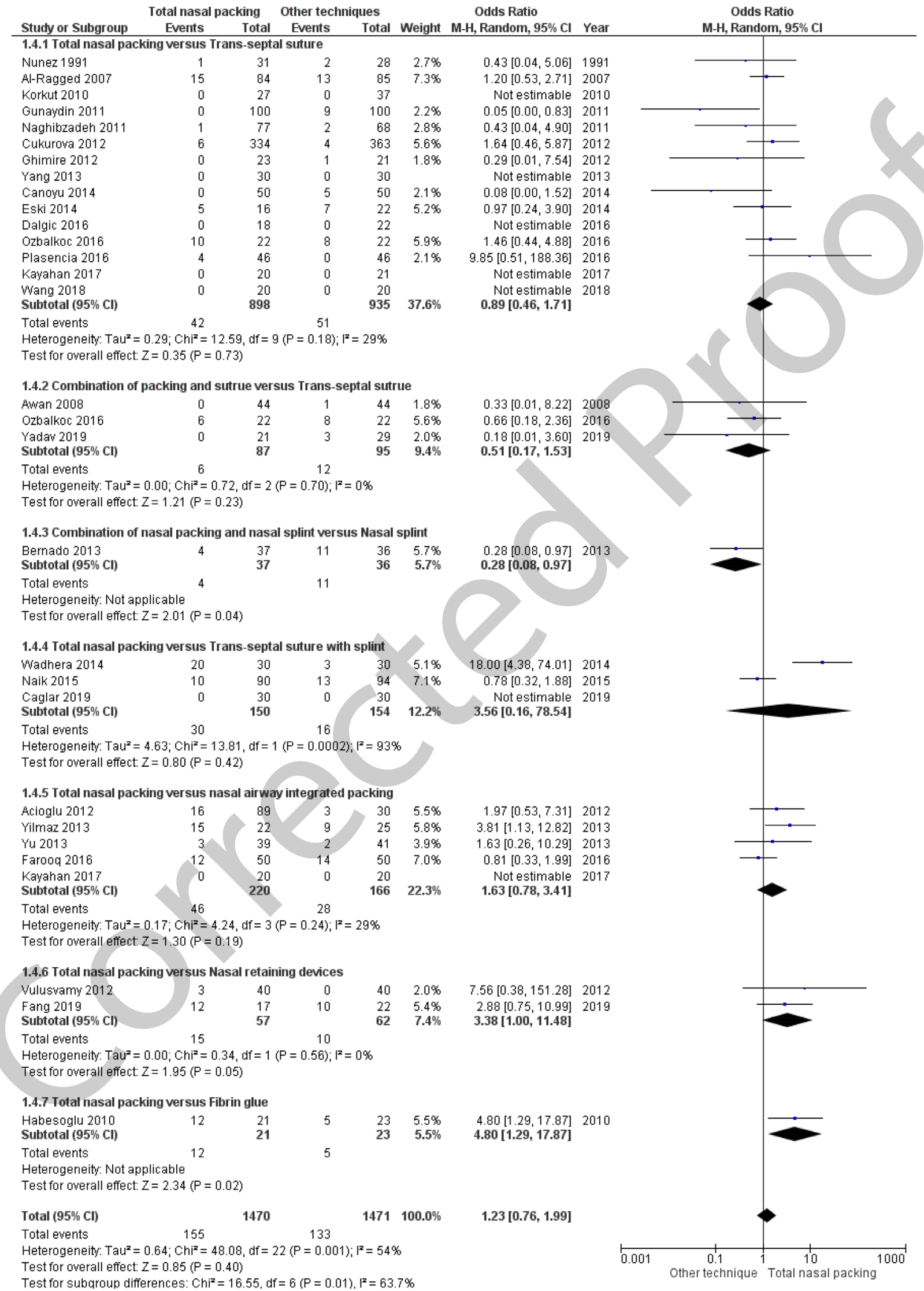


E-figure 3. Hematoma, odds ratio (OR), Total nasal packing versus other techniques: random-effect model.

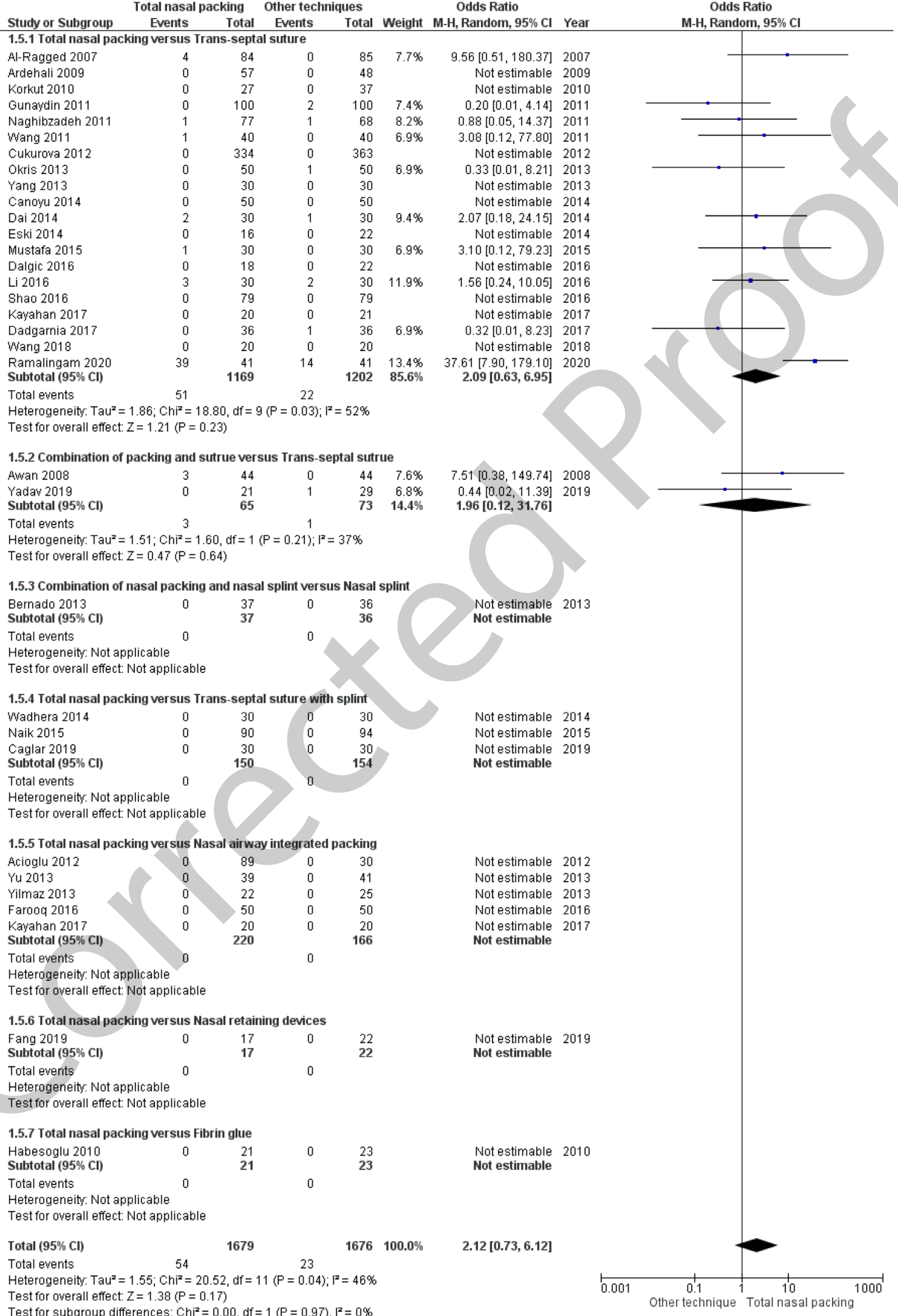


E-figure 4. Sleep disturbance, odds ratio (OR), Total nasal packing versus other techniques: random-effect model.

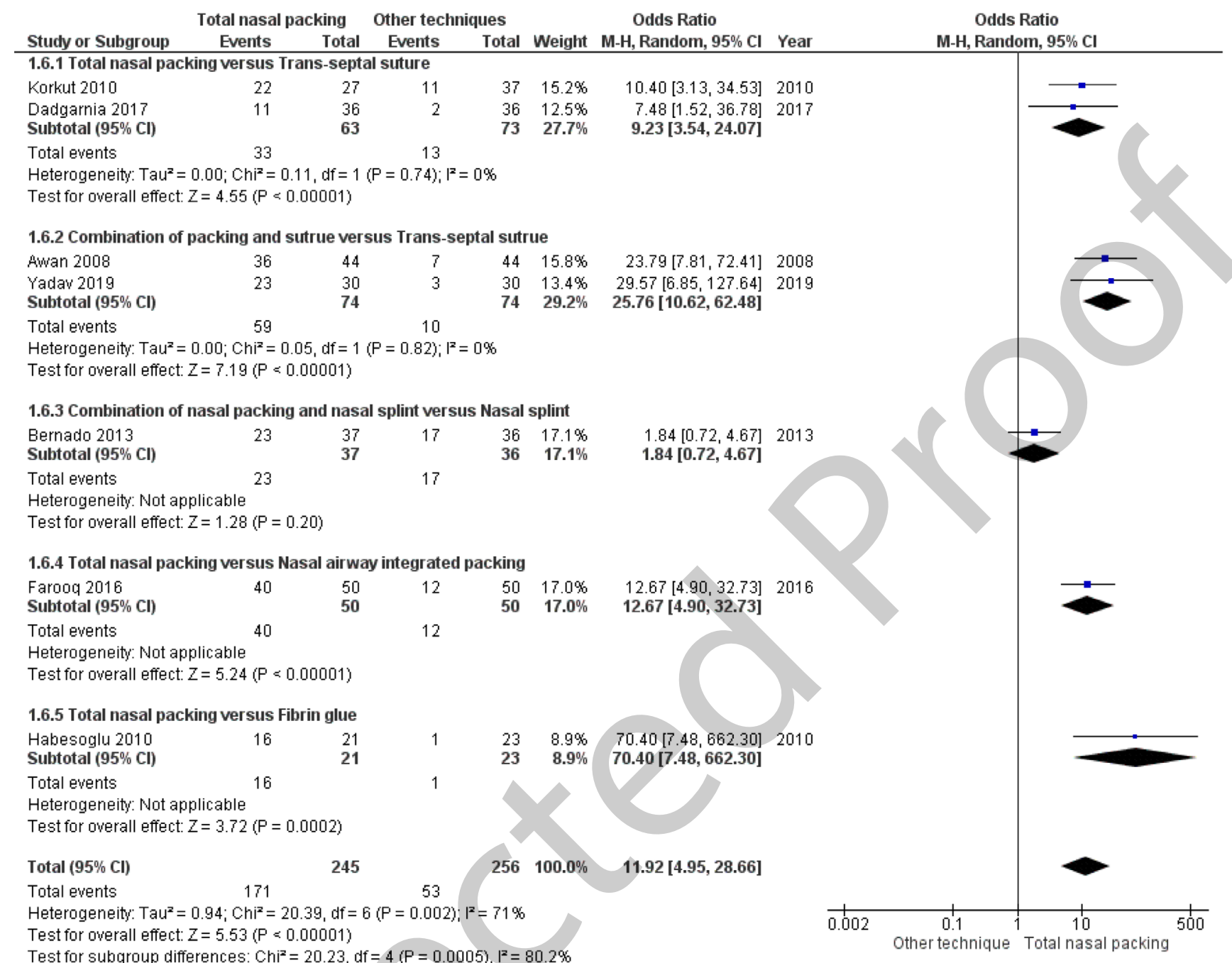


E-figure 5. Infection, odds ratio (OR), Total nasal packing versus other techniques: fixed-effect model.

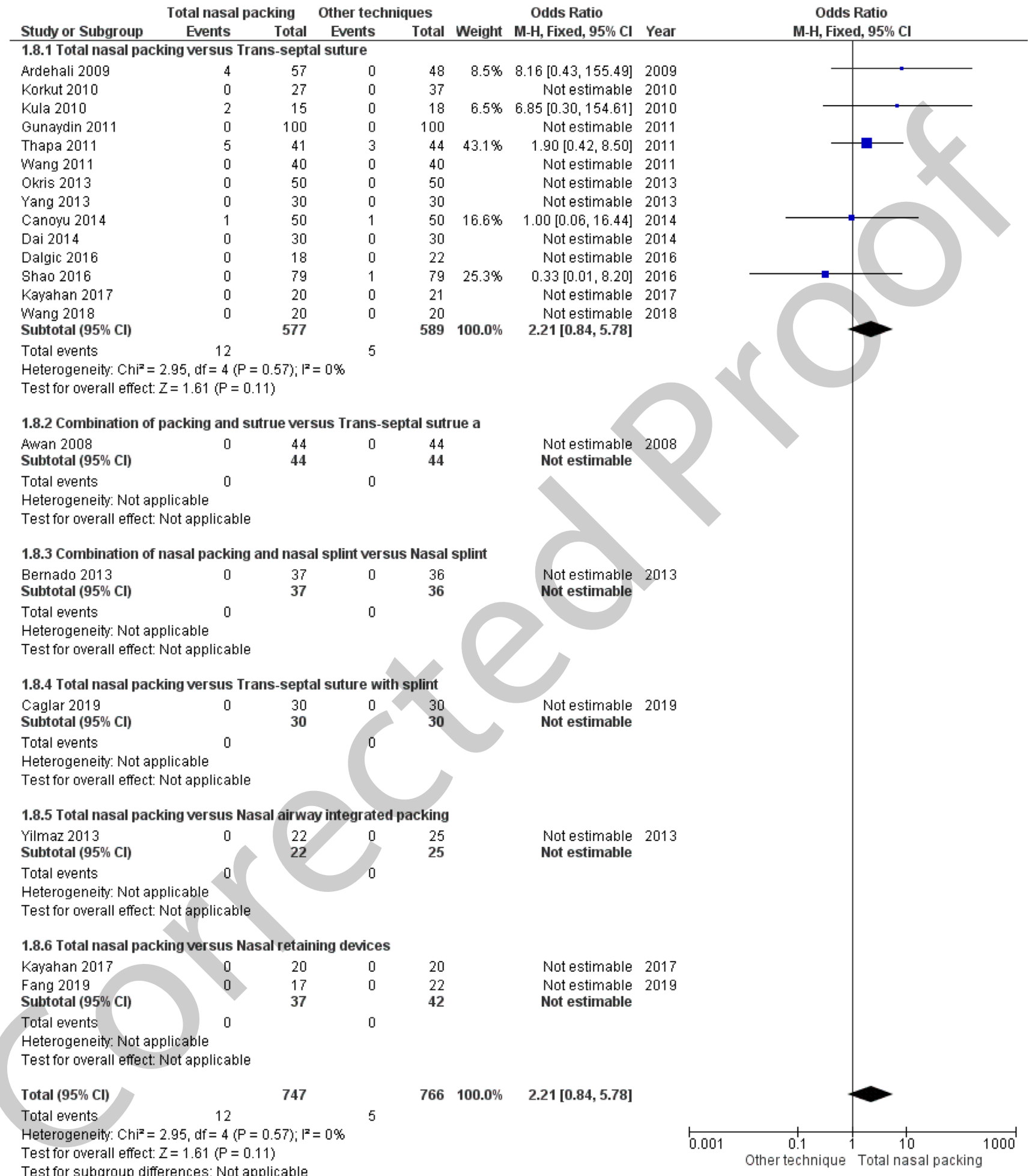


E-figure 6. Crusting, odds ratio (OR), Total nasal packing versus other techniques: random-effect model.

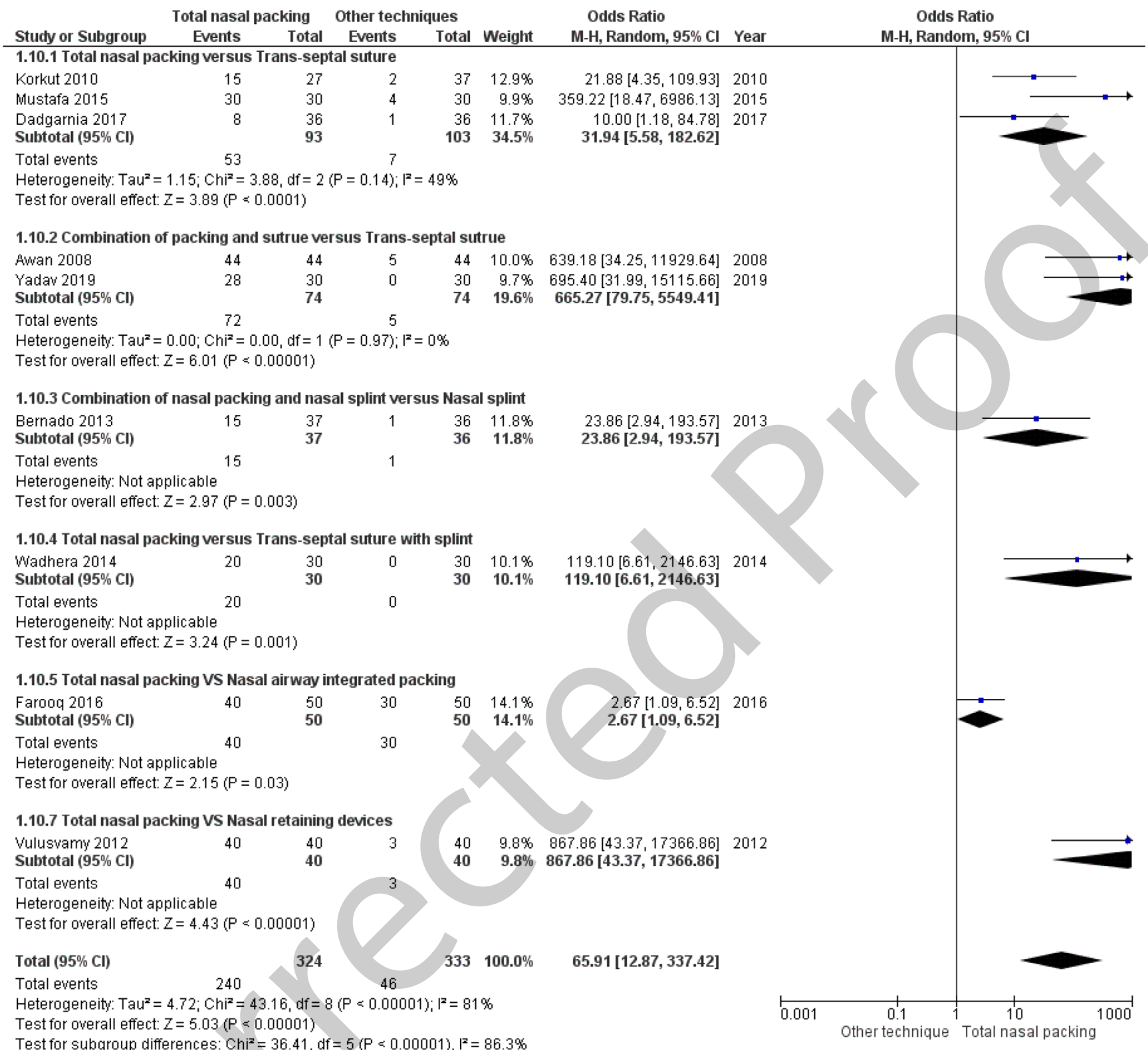


E-figure 7. Epiphora, odds ratio (OR), Total nasal packing versus other techniques: random-effect model.

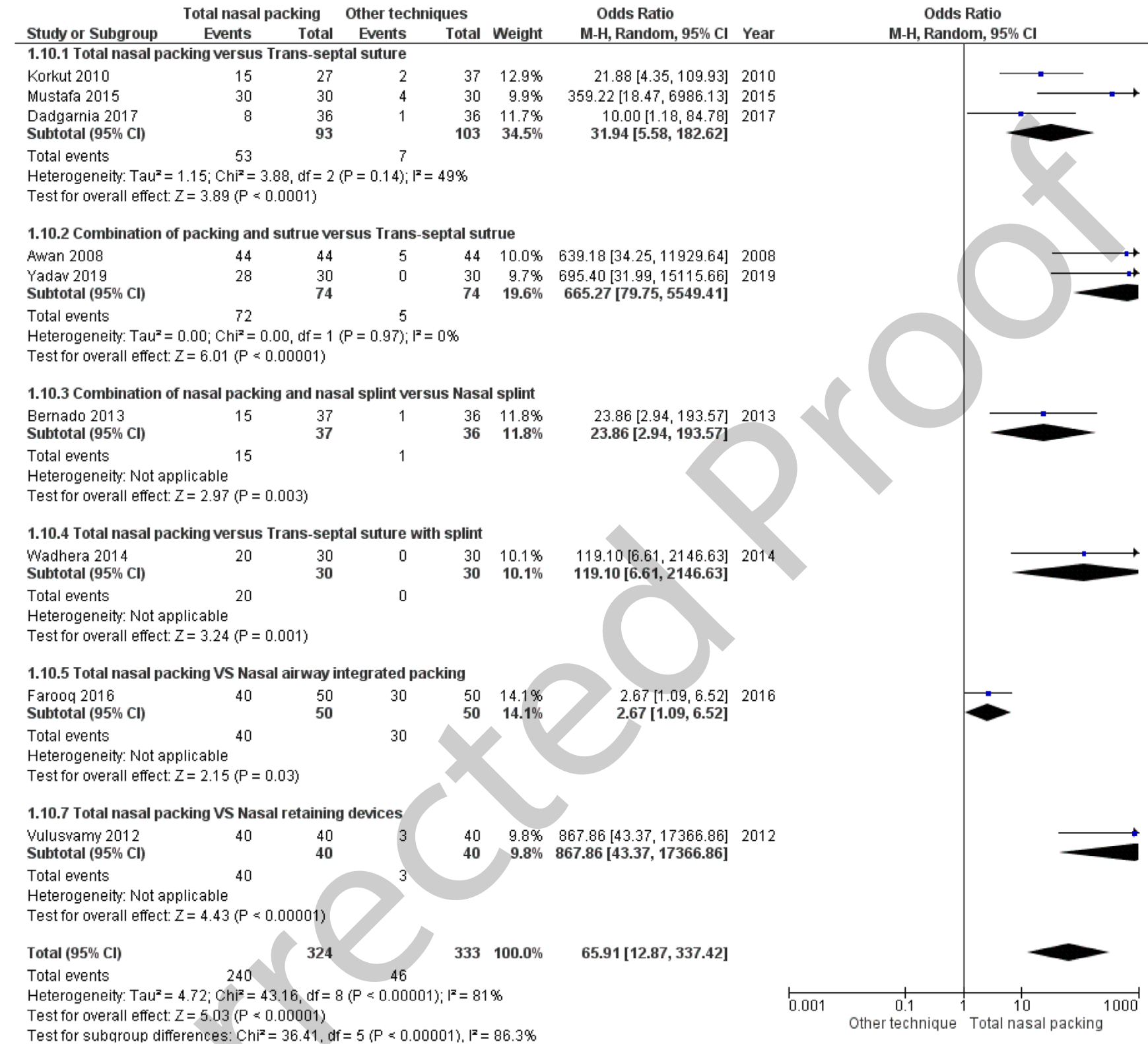


E-figure 8. Dysphagia, odds ratio (OR), Total nasal packing versus other techniques: random-effect model.

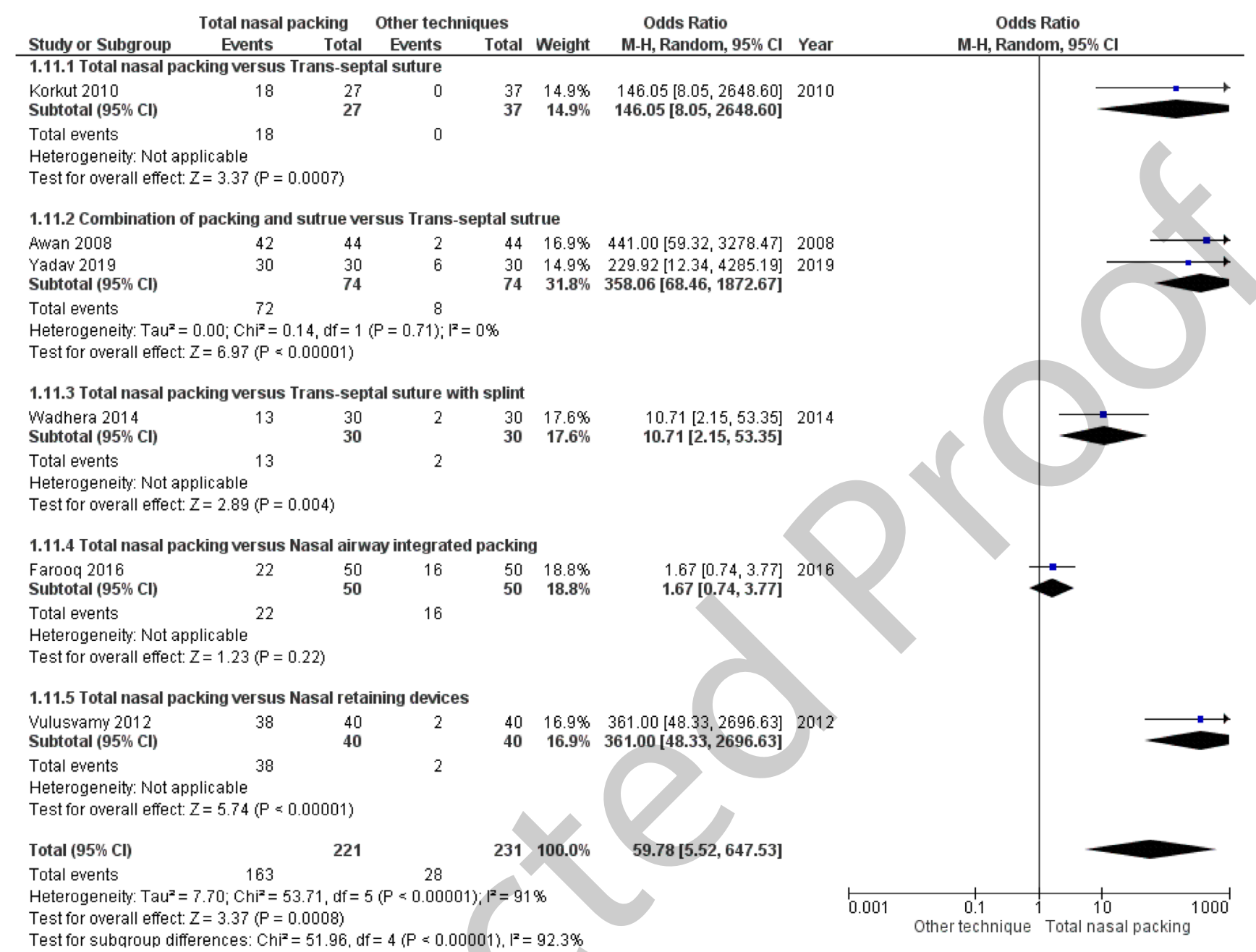


E-figure 9. Perforation, odds ratio (OR), Total nasal packing versus other techniques: fixed-effect model.

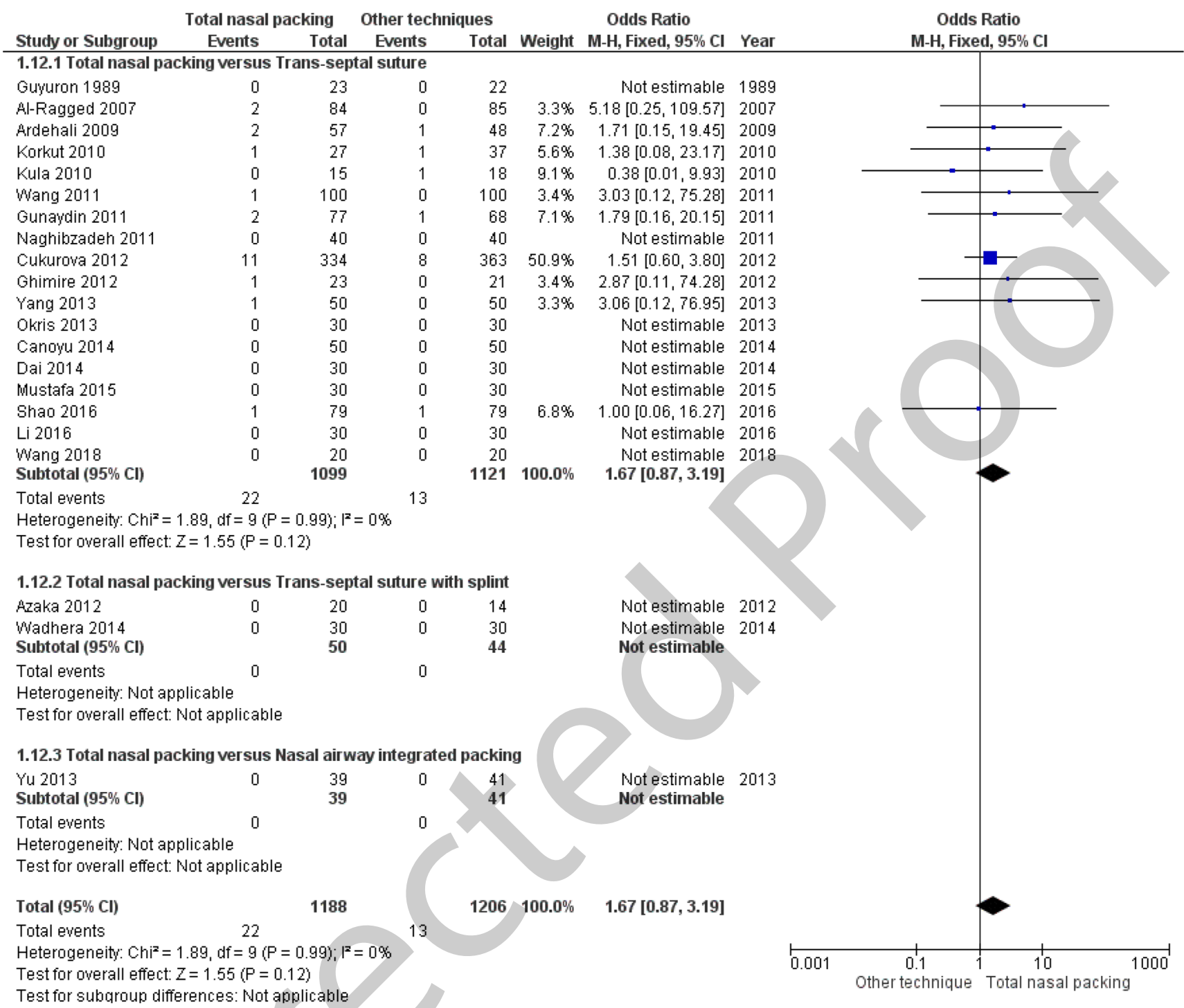


E-figure 10. Residual septal deviation, odds ratio (OR), Total nasal packing versus other techniques: fixed-effect model.

Total packing Other techniques

Study or Subgroup Events Total Events

1.14.1 Total nasal packing versus Trans-septal suture

Guyuron 1989

Al-Ragged 2007

Ardehali 2009

Wang 2011

Naghibzadeh 2011

Ghimire 2012

Yang 2013

Dai 2014

Shao 2016

Dadgarnia 2017

Wang 2018

Subtotal $(95 \% \mathrm{Cl})$

Total events

Test for owerall effect: $Z=0.30(P=0.77)$

1.14.2 Total nasal packing versus Trans-septal suture with splint Wadhera 2014

Subtotal (95\% Cl)

Total events

$0 \quad 79$
79

79

0

79
79

D

Heterogeneity: Not applicable

Test for owerall effect: Not applicable

1.14.3 Total nasal packing versus Nasal retaining device

Vulusvamy 2012

Subtotal $(95 \% \mathrm{Cl})$

Total events

340

40

3

$40 \quad 7.6 \%$

$1.00[0.19,5.28]-2012$

Heterogeneity: Not applicable

Test for owerall effect: $Z=0.00(P=1.00)$

Total $(95 \% \mathrm{Cl})$

569

3

Total events

40

40

$549 \quad 100.0 \%$

$13.3 \%$

$10.0 \%$

$2.5 \%$

$21.8 \%$

$28.1 \%$

$4.0 \%$

Odds Ratio

H, Fixed, 95\% Cl Year

$1.01[0.28,3.63] 1989$

$1.01[0.29,3.55] 2007$

$0.73[0.15,3.51] 2009$

$3.22[0.32,32.89] 2011$

Not estimable 2011

$0.22[0.05,0.95] 2012$

$0.69[0.27,1.77] 2013$

$5.09[0.98,26.43] 2014$

Not estimable 2016

Not estimable 2017

Not estimable 2018

$92.4 \% \quad 0.93[0.57,1.51]$
Not estimable 2014 Not estimable

Heterogeneity: $\mathrm{Chi}^{2}=9.44, \mathrm{df}=7(\mathrm{P}=0.22) ;\left.\right|^{2}=26^{\circ}$

Test for owerall effect: $Z=0.28(P=0.78)$

Test for subcroup differences: $\mathrm{Ch}^{\mathbf{z}}=0.01, \mathrm{df}=1(\mathrm{P}=0.93)^{\mathrm{z}}=0 \%$

Odds Ratio

M-H, Fixed, $95 \% \mathrm{Cl}$

M-H, Fixed, $95 \% \mathrm{Cl}$

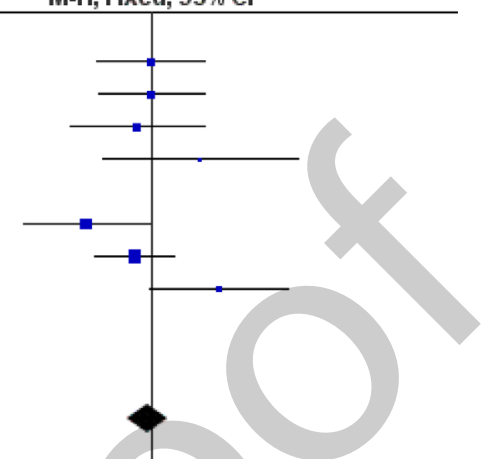


E-figure 11. Pain severity VAS 0-10, mean difference (MD) Total nasal packing versus other techniques: random-effect model.

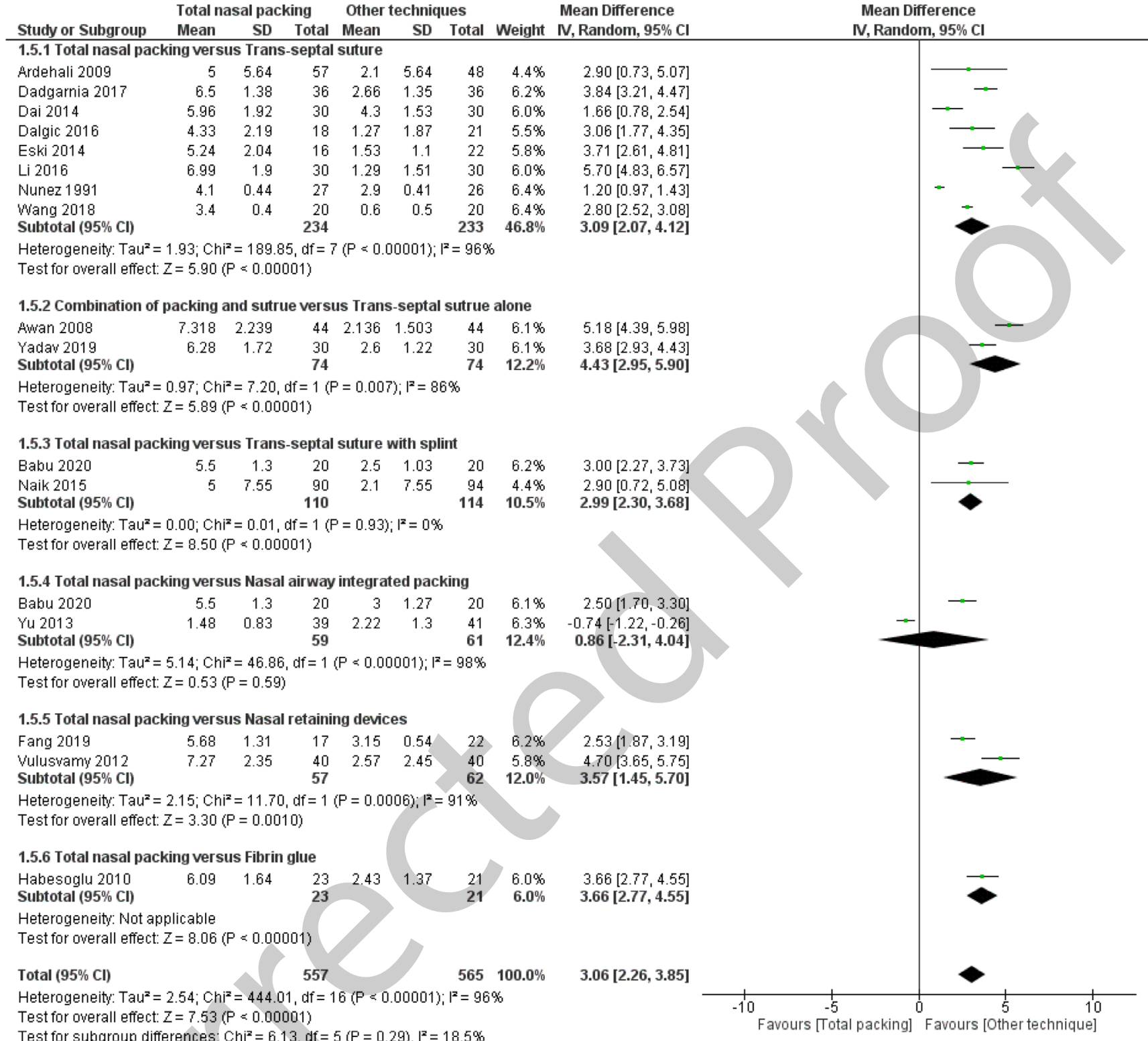


E-figure 12. Funnel plots: all outcomes.

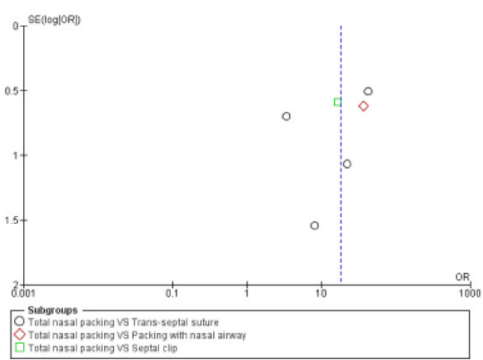

respiratory distress

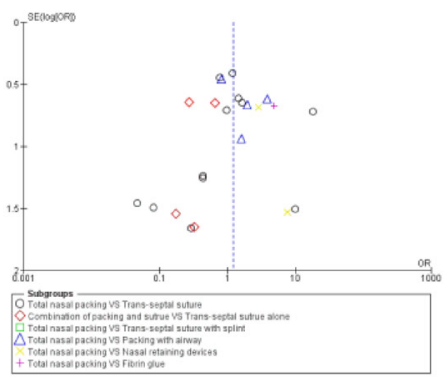

Bleeding

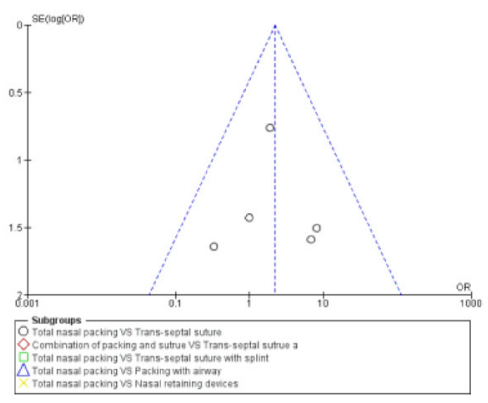

Infection

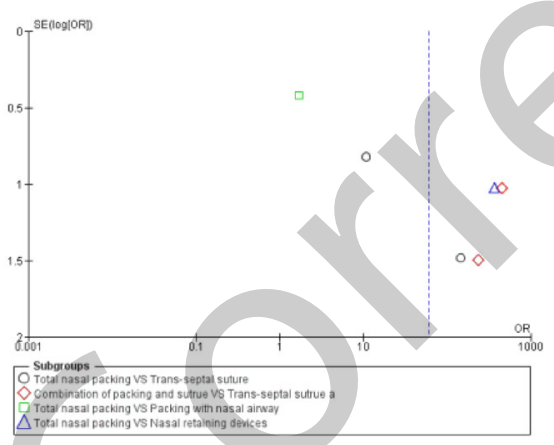

Dysphagia

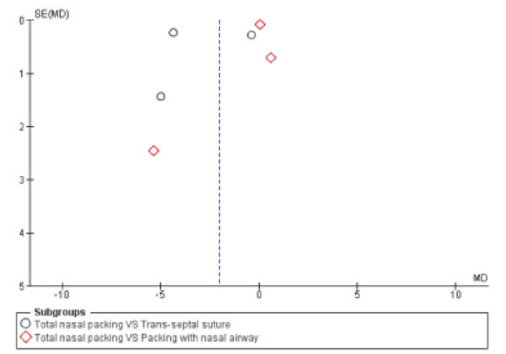

oxygen saturation

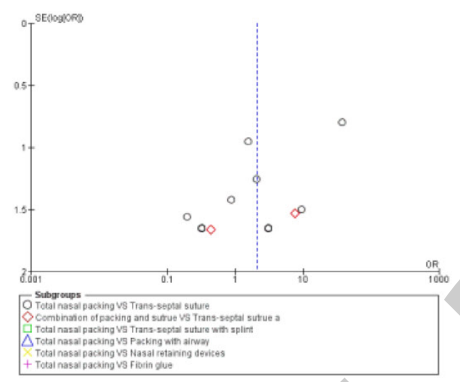

Hematoma

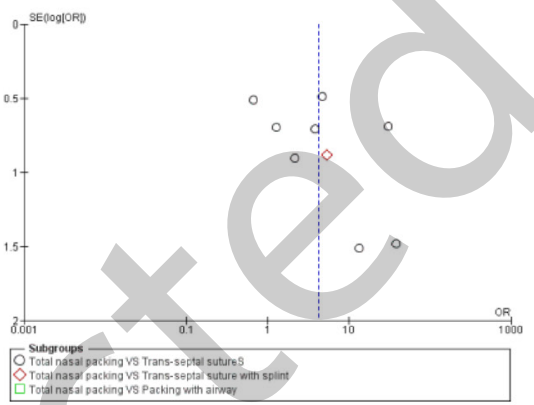

Crusting

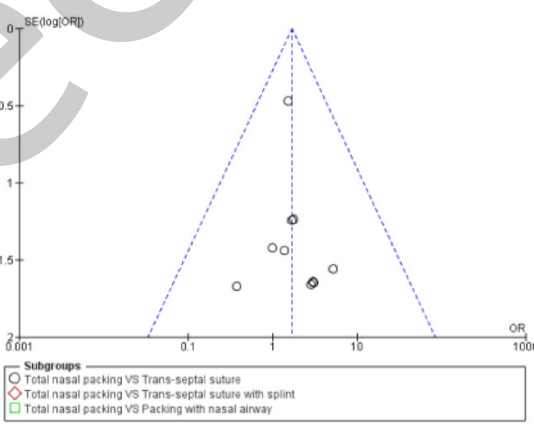

Perforation

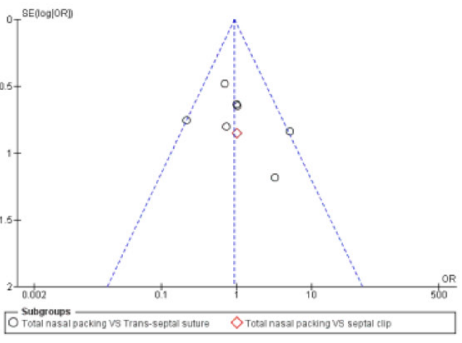

Residual septal deviation

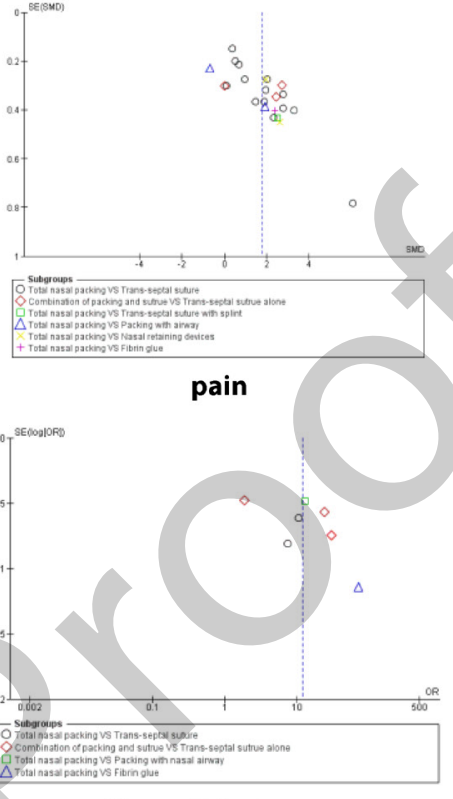

Sleep disturbance

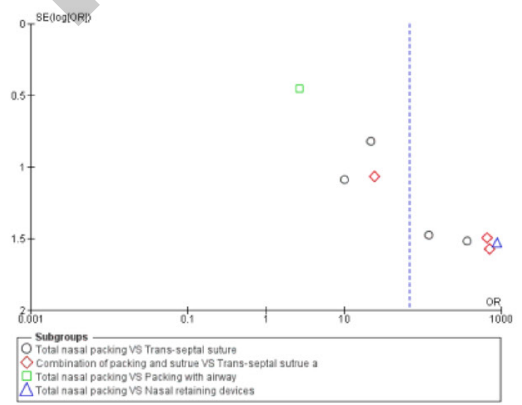

Epiphora

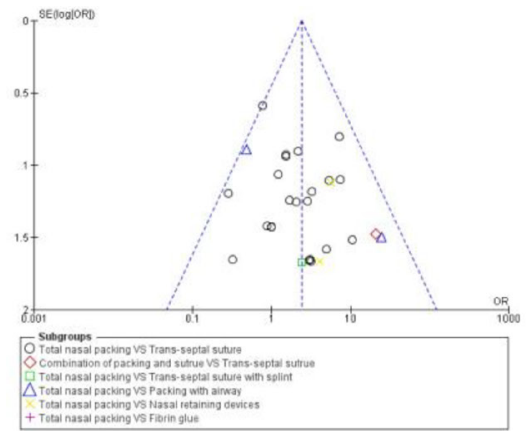

Adhesion 